\title{
Social cognition in a case of amnesia with neurodevelopmental mechanisms
}

\author{
Angelica Staniloiu ${ }^{1}{ }^{*}$, Sabine Borsutzky ${ }^{1}$, Friedrich G. Woermann ${ }^{2}$ and Hans J. Markowitsch ${ }^{1,3,4}$ \\ 1 Physiological Psychology, University of Bielefeld, Bielefeld, Germany \\ ${ }^{2}$ MRI Unit, Bethel Epilepsy Center, Bielefeld, Germany \\ ${ }^{3}$ Institute for Advanced Science, Delmenhorst, Germany \\ ${ }^{4}$ Center of Excellence Cognitive Interaction Technology, University of Bielefeld, Bielefeld, Germany
}

\section{Edited by:}

R. Nathan Spreng, Cornell

University, USA

Reviewed by:

Asaf Gilboa, Rotman Research Institute at Baycrest, Canada

Elisa Ciaramelli, Università di

Bologna, Italy

*Correspondence:

Angelica Staniloiu, Physiological Psychology, University of Bielefeld, POB 100131, 33501 Bielefeld,

Germany

e-mail: astaniloiu@uni-bielefeld.de
Episodic-autobiographical memory (EAM) is considered to emerge gradually in concert with the development of other cognitive abilities (such as executive functions, personal semantic knowledge, emotional knowledge, theory of mind (ToM) functions, language, and working memory). On the brain level its emergence is accompanied by structural and functional reorganization of different components of the so-called EAM network. This network includes the hippocampal formation, which is viewed as being vital for the acquisition of memories of personal events for long-term storage. Developmental studies have emphasized socio-cultural-linguistic mechanisms that may be unique to the development of EAM. Furthermore it was hypothesized that one of the main functions of EAM is the social one. In the research field, the link between EAM and social cognition remains however debated. Herein we aim to bring new insights into the relation between EAM and social information processing (including social cognition) by describing a young adult patient with amnesia with neurodevelopmental mechanisms due to perinatal complications accompanied by hypoxia. The patient was investigated medically, psychiatrically, and with neuropsychological and neuroimaging methods. Structural high resolution magnetic resonance imaging revealed significant bilateral hippocampal atrophy as well as indices for degeneration in the amygdalae, basal ganglia, and thalamus, when a less conservative threshold was applied. In addition to extensive memory investigations and testing other (non-social) cognitive functions, we employed a broad range of tests that assessed social information processing (social perception, social cognition, social regulation). Our results point to both preserved (empathy, core ToM functions, visual affect selection, and discrimination, affective prosody discrimination) and impaired domains of social information processing (incongruent affective prosody processing, complex social judgments). They support proposals for a role of the hippocampal formation in processing more complex social information that likely requires multimodal relational handling.

Keywords: episodic-autobiographical memory, social information processing, theory of mind, hippocampus, hypoxia

\section{INTRODUCTION}

Memory is divided according to time and content axes, respectively (Markowitsch and Staniloiu, 2012). Along the content axis, five long-term memory systems were described [procedural, priming, perceptual, semantic, and episodic-autobiographical memory (EAM) systems] (Tulving, 2005). These systems are considered to build up on each other ontogenetically and phylogenetically. EAM is considered the last ontogenetic and phylogenetic achievement (Nelson, 2003, 2005; Nelson and Fivush, 2004; Tulving, 2005). It is currently defined as being the conjunction of subjective time, autonoetic consciousness, and the experiencing self (Tulving, 2005). Autonoetic consciousness has been conceptualized in slightly different ways. Wheeler et al. (1997, p. 335) defined it as the "capacity that allows adult humans to mentally represent and to become aware of their protracted existence across subjective time." Lemogne et al. (2006, p. 260) stated that autonoetic consciousness entails a "sense of self in time and the ability to relive subjective experiences from the encoding context by mentally traveling back in time." Markowitsch proposed that autonoetic consciousnes is characterized by a superior ability to reflect upon oneself and distinguish oneself from the social and biological environment (Markowitsch, 2003; Markowitsch and Staniloiu, 2011a). While the latter definition of autonoetic consciousness might suggest a link between EAM and the dialectic of self and others (Suddendorf et al., 2009), the relationship between EAM (Tulving, 2005; Markowitsch and Staniloiu, 2012) and social cognition [theory of mind (ToM), empathy, simulation, social judgment, moral judgment] (Adolphs, 2010a) remains debated, and insufficiently explored experimentally.

Several authors proposed that EAM or autonoetic consciousness modulate an individual's capacity to make inferences about others' mental states and feelings, and distinguish these states from 
his or her own ones (Batson et al., 1996; Bluck et al., 2005; Saxe et al., 2006; Staniloiu et al., 2010a). Tulving (2005) remarked that Darwin's description of "moral being" had alluded to several features, which may be tied to morality, such as the capability for recollecting the past, the capacity for autonoetic consciousness and the ability to subjectively mentally travel in time, both into past and future. In this vein, difficulties with recollecting emotional events and/or autonoetic consciousness were propounded to exist in offenders with psychopathy, who feature impairments in empathy and affective ToM (Shamay-Tsoory and Aharon-Peretz, 2007; Craig et al., 2009). Croft et al.'s (2010) results suggested that severe EAM impairments due to neurological incidents may affect the updating of moral character judgments and subsequently may influence the way these individuals perceive and behave toward others. The authors compared in their study the performance of patients with bilateral damage to the ventromedial prefrontal cortex to that of patients with bilateral damage to the hippocampal formation (due to hypoxia/anoxia or herpes viral encephalitis) and that of a control brain-damaged group during a task that required the participants to make moral judgments about unfamiliar persons in two conditions (before and after being exposed to various social context scenarios). In contrast to patients with bilateral damage to the ventromedial prefrontal cortex, patients with bilateral hippocampal damage presented with severe impairments in conscious mnemonic processing, interfering with their everyday life. During the moral updating task, they furthermore demonstrated the largest amount of change in moral judgments after social scenario manipulations, compared to patients with bilateral damage to the ventromedial prefrontal cortex, who showed the least amount of change.

Social cognition (ToM) deficits were reported to co-occur with memory impairments in several psychiatric conditions, including dissociative (functional) amnesia (Corcoran and Frith, 2003; Reinhold and Markowitsch, 2007, 2008, 2009; Fujiwara et al., 2008). Kritchevsky et al. (2004, p. 224) described a patient with functional amnesia who after the onset of amnesia became "less aware of the feelings of other individuals." He furthermore did not comprehend jokes anymore and "interpreted them literally" (Kritchevsky et al., 2004, p. 224). Interpersonal difficulties with family members have been reported to occur after the onset of dissociative amnesia and were partly attributed to an impaired ability to properly read the familiar/close others' mental states (Rabin and Rosenbaum, 2012; Staniloiu and Markowitsch, 2012; Markowitsch and Staniloiu, 2013).

Reinhold and Markowitsch (2007) formally assessed emotional processing and social cognition in two female adolescents (age 16 and 18, respectively) suffering from dissociative amnesia. They found that both patients were impaired on the German-language adaptation of the Reading the Mind in the Eyes Test (RMET) (Baron-Cohen et al., 2001; Fleck et al., 2002; Dziobek et al., 2006; Fujiwara et al., 2008) and emotional evaluation of ToM stories (Kalbe et al., 2007). In a case series of five patients with dissociative (functional) amnesia, three out of the four patients in whom the RMET was administered, showed performance deficits on it. Dissociative amnesia is however often accompanied by other psychiatric or medical comorbidities, such as major depressive disorder (Staniloiu and Markowitsch, 2012). One could furthermore argue that, even when the co-occurring symptoms of depression do not reach the threshold for a diagnosis of an affective disorder according to the international nosologies' diagnostic criteria (socalled subclinical symptoms of depression), they can still impact on ToM functions (Cusi et al., 2011). It was speculated that in some psychopathological conditions (Corcoran and Frith, 2003), which are known to have a neurodevelopmental basis, the co-occurrence of EAM and ToM deficits may reflect a developmental arrest of closely in time emerging neurocognitive functions, which are at that stage functionally interdependent (Perner, 2000; Bird et al., 2004; Nelson and Fivush, 2004). Other authors proposed that in certain forms of psychopathologies, an idiosyncratic way of making inferences about the mental states of others might take place, due to a failure of inhibition of own perspective and/or a poverty of models of the inner world of others (Newen and Schlicht, 2009). Functional neuroimaging studies suggested common (but also distinct) neural substrates for EAM and ToM (Spreng et al., 2008; Rabin et al., 2010; Spreng and Grady, 2010; Abu-Akel and Shamay-Tsoory, 2011). A recent investigation of healthy female participants revealed that the degree of neural overlap depends on the target person involved in the ToM task; when participants engaged in making inferences about the mental states of familiar others as opposed to unfamiliar others, they seemed to recruit more EAM-related brain areas, suggesting the use of a different cognitive strategy (despite identical task instructions) (Rabin and Rosenbaum, 2012).

By contrast, there are reports of patients with amnesia secondary to neurological brain insults incurred in adulthood with no detectable deficit on ToM functions (as assessed by using standardized laboratory tasks). Rosenbaum et al. (2007) investigated with a battery of widely employed tests (Stone et al., 1998; Castelli et al., 2000; Baron-Cohen et al., 2001; Dennis et al., 2001; Stuss et al., 2001) two patients with amnesia with onset after severe traumatic brain injury [patient K.C. (Rosenbaum et al., 2005) and patient M. L. (Levine et al., 1998, 2009)] and found that their performance did not significantly differ from that of 14 control participants on all measures. In addition, despite speculations that social cognition and EAM might depend on each other during early development (Perner, 2000; Nelson and Fivush, 2004), a recent study of an adult female patient $(\mathrm{HC})$ with developmental amnesia showed that the patient performed within normal limits on a variety of standardized tests that assessed her capacity for ToM (Rabin et al., 2012). The applied testing battery consisted of: the False belief and the Faux pas tests (Stone et al., 1998), the 36 black and white photographs variant of the RMET (Baron-Cohen et al., 2001), the Sarcasm and Empathy Test (Dennis et al., 2001), the Visual Perspective-Taking and Deception Test (Stuss et al., 2001), and the Animation Test (Castelli et al., 2000).

The term developmental amnesia is a non-DSM-IV-TR (2000) terminology that designates a syndrome that occurs in childhood and is caused by relatively selective damage to hippocampi (usually resulting in more than $30-40 \%$ bilateral volume reduction of hippocampi in comparison to controls). Some involvement of the basal ganglia (bilaterally), thalamus (bilaterally), and right retrosplenial cortex, which was demonstrated in voxelbased morphometry studies had been reported as well (VarghaKhadem et al., 1997, 2003; Isaacs et al., 2003). Consistent with the hypoxia-anoxia pathogenetic model (see below), in a patient with developmental amnesia white matter changes (e.g., thinning 
of the corpus callosum) were additionally remarked and in another cerebellar atrophy was noted (Vargha-Khadem et al., 1997; Gadian et al., 2000; Connolly et al., 2007).

The most common cause of relatively selective hippocampi damage is single or recurrent episodes of ischemic-hypoxia, which were reported to occur perinatally or in childhood until prepubertal period. Affected children can still acquire knowledge about facts and language skills depending on their intellectual ability that can range from low to normal, but show severe impairments in the episodic-autobiographical domain and everyday memory (Markowitsch and Staniloiu, 2012; Willoughby et al., 2012).

Most recently, studies of young adults with childhood developmental amnesia have focused on investigating the ability to imagine the future and on distinguishing between recollection/recall and familiarity/recognition (Kwan et al., 2010; Maguire et al., 2010). Little has, however, been devoted to a thorough investigation of social information processing in these cases, according to our knowledge.

Herein we provide a review, interpretation and critical discussion of results obtained with various tasks tapping on social cognition as well as other aspects of social information processing in a young adult male patient with amnesia with neurodevelopmental mechanisms. When we speak of social information processing, we use as guiding framework the classification described in Table $\mathbf{1}$ of Adolphs (2010a). In this table, Adolphs (2010a) depicted the following three stages of social information processing: social perception (perception of pheromones, face and speech perception, and perception of social touch and biological motion), social cognition (affective and cognitive ToM, simulation, empathy, social judgment, moral judgment), and social regulation (cognitive control, emotion regulation, monitoring/error correction, self-reflection, deception).

\section{CASE REPORT}

ML is a 29 -year-old man who was 27 -year-old at the time of the neuropsychological testing in our clinic. He is the oldest of three children, coming from a middle class family. Both of his siblings achieved higher education. His parents divorced when ML was a teenager. ML was born prematurely, at 33 weeks of gestation. After birth, he required a 2-week hospitalization for lung immaturity in a neonatal intensive care unit, where he received oxygen therapy. In terms of developmental milestones, ML began talking at age 13 months. Some stuttering was noted in childhood, but it ceased later on. From age 3 months until age 1 year, ML received physical therapy for problems with motor tone and muscle coordination. Sitting was delayed (he was older than 1 year when he was able to sit). He began walking at age 18 months and completed toilet training at age 3 years. At age 2 years, ML underwent another course of physical therapy. Both therapies followed the model developed by Vaclav Vojta (Sadowska, 2001) and were successful; however they were perceived by ML's mother as having been psychologically traumatizing. Clumsiness and other (usually transient) problems with motor skills were reported in other patients with developmental amnesia, who sustained hypoxic-ischemic events during the first year of life (Gadian et al., 2000; Vargha-Khadem et al., 2003). However, the reported difficulties were milder than the ones experienced by ML. Although postulated, a connection between the basal ganglia (and thalamic) damage and motor impairment in cases of developmental amnesia remained unclear (Gadian et al., 2000; Vargha-Khadem et al., 2003; de Haan et al., 2006).

ML entered kindergarten at age 4 years and was described during those time as being reserved and a daydreamer. Since age five ML has seen several health care providers and has been suspected of having several diagnoses such as Minimal Cerebral Dysfunction (MCD), autistic spectrum disorder, Asperger's syndrome, attention hyperactivity deficit disorder. None of these diagnoses was confirmed. ML's case may therefore reflect other cases of developmental amnesia from the literature, where an accurate diagnosis was far from being "straightforward" from the beginning (Gadian et al., 2000). As Gadian et al. (2000) remarked, it is not uncommon for problems with episodic memory-which typically become evident around age 5 or 6 years (in conformity with data on the ontogenesis of episodic memory; Nelson and Fivush, 2004) - to be initially attributed to attention deficits. Several motor tics and substantial problems with school performance were noted when ML was around the age of 7 years, shortly after he had entered the school. Problems with organization, memory for life events as well as performing several real-world memory tasks (Willoughby et al., 2012) were remarked. In the absence of a comprehensive and rigorous neuropsychological investigation at the time, ML's poor school functioning initially was however conjectured to reflect primary attention and concentration difficulties (Lebrun-Givois et al., 2008). On an interpersonal level, ML reportedly experienced difficulties establishing social contact with other peers during his early school years. He often imitated emotions or behaviors of others, instead of expressing his own feelings. Although not commonly reported, social and emotional difficulties were described in other patients with diagnoses of developmental amnesia by other authors (Picard et al., 2012).

ML later on outgrew his tics. Because of his persisting difficulties in school, ML was supervised by a school psychologist. In the following years, ML continued to experience memory impairments and lack of organization. Despite of otherwise good intellectual functions, he continued to fail school, which prompted his family to seek psychiatric help for him. Therefore, at age 16 years ML was brought by his mother for a comprehensive medical and neuropsychological assessment. Contrary to expectations, the neuropsychological assessment revealed above average attention and concentration abilities; verbal short-term memory was average, digit span was above average, his visual short-term memory was average and word fluency was within normal limits. ML was fully oriented. Verbal and visual memory performance after delays of half an hour were however impaired. ML displayed no evidence of distractibility and showed no heightened level of interference. There was no evidence of perseveration or apraxia, stereotypes, or tics. The neuropsychologist's recommendation was that ML should undergo memory rehabilitation training, although no clear diagnosis was provided.

A routine electroencephalography (EEG), which was performed at the time, yielded no evidence of seizures or epilepsy. Both computer tomography (CT) and magnetic resonance imaging (MRI) scans of the head were performed. The CT showed a discrete enlargement of the lateral ventricles downright. MRI revealed a small gliotic mass in the left thalamus and discrete prominence of 
Table 1 | Summary of test results.

\begin{tabular}{|c|c|c|c|c|c|c|c|}
\hline Test & Result & $\begin{array}{l}\text { Below } \\
\text { average } \\
(\mathrm{PC}<16)\end{array}$ & $\begin{array}{l}\text { Low } \\
\text { average } \\
(P C=16-24)\end{array}$ & $\begin{array}{l}\text { Average } \\
(\mathrm{PC}=\mathbf{2 5 - 7 5 )}\end{array}$ & $\begin{array}{l}\text { High } \\
\text { average } \\
\text { (PC = 76-84) }\end{array}$ & $\begin{array}{l}\text { Above } \\
\text { average } \\
(\mathrm{PC}>84)\end{array}$ & Remark(s) \\
\hline
\end{tabular}

\section{LATERALITY}

Laterality-preference-inventary

Eye

Ear

Hand

Foot

Questionnaire for measuring motor

asymmetry

Handedness

Footedness

\section{LANGUAGE}

Boston naming test

PERCEPTION

Judgment of line orientation

Correct

False

\section{NUMBER CALCULATION AND ARITHMETICS}

ZRT

Number processing

Written transcoding

Calculation

Calculation by heart

Written calculation

INTELLECTUAL FUNCTIONS

Non-verbal

LPS-4 (logical thinking)

Mosaic-test (HAWIE-R)

Matrices-test
Score $=+4$ (scores reach from -4 [left] via 0 [ambidexter] to +4 [right])

Score $=-4$

Score $=-2$

Score $=+4$
Clearly right oriented Clearly right oriented More left oriented

Clearly right oriented
Score $=-16$ ( +8 to +20 : right, -7 to +7 : symmetrical, -8 to -20 : left $)$

Score $=0$ ( +4 to +2 : right, -1 to +1 : symmetrical, -2 to -4 : left $)$
Left

Symmetrical
57 Out of 60 items

35

0

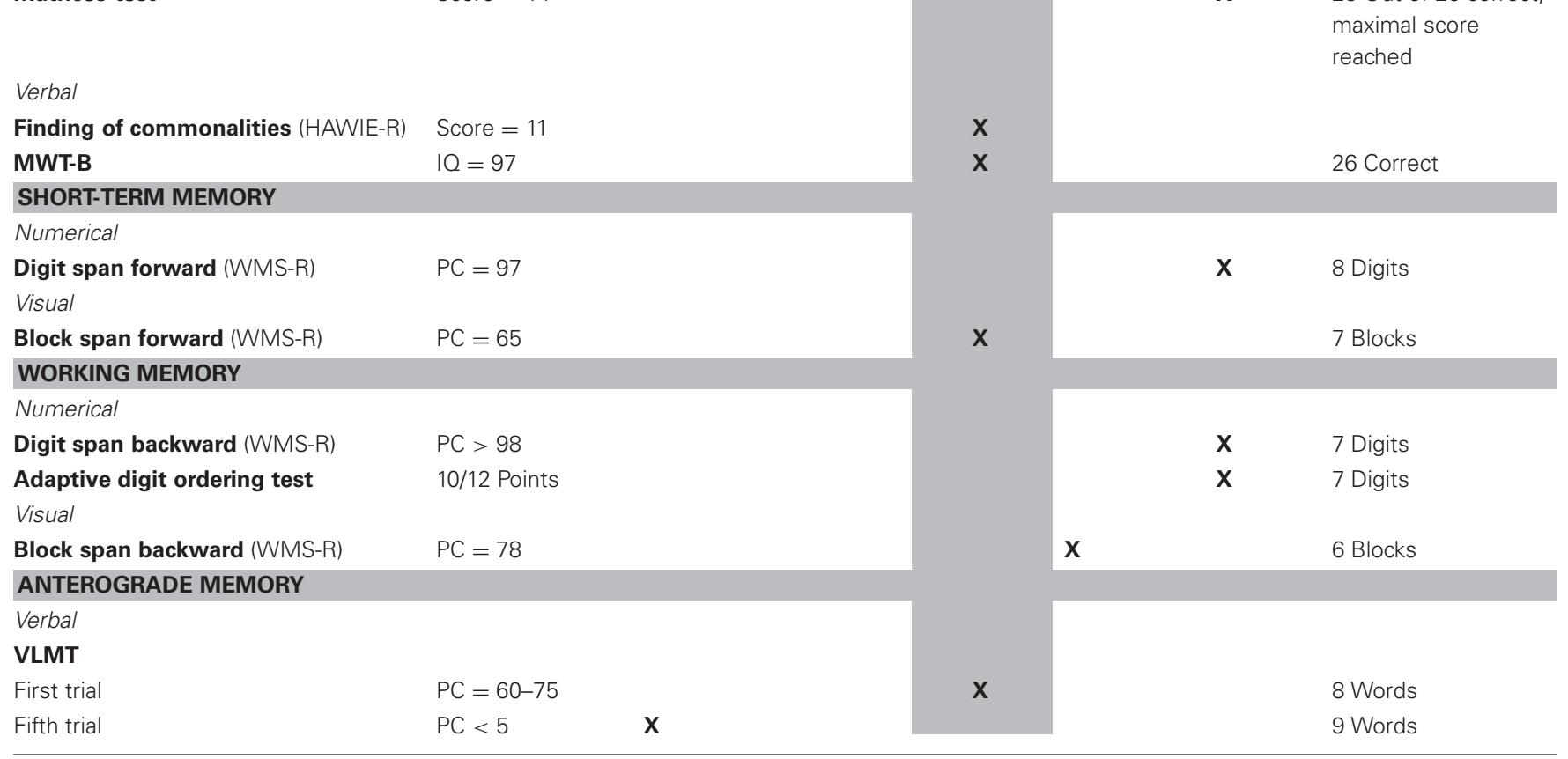


Table 1 | Continued

\begin{tabular}{|c|c|c|c|c|c|c|c|}
\hline Test & Result & $\begin{array}{l}\text { Below } \\
\text { average } \\
(\mathrm{PC}<16)\end{array}$ & $\begin{array}{l}\text { Low } \\
\text { average } \\
(P C=16-24)\end{array}$ & $\begin{array}{l}\text { Average } \\
(P C=25-75)\end{array}$ & $\begin{array}{l}\text { High } \\
\text { average } \\
(P C=76-84)\end{array}$ & $\begin{array}{l}\text { Above } \\
\text { average } \\
(\mathrm{PC}>84)\end{array}$ & Remark(s) \\
\hline Interference list & $P C=85$ & & & & & $\mathbf{x}$ & 9 Words \\
\hline Direct recall & $P C=0$ & $\mathbf{x}$ & & & & & 1 Word \\
\hline Forgetting rate (trial 5 - delayed recall) & $P C=0$ & $\mathbf{x}$ & & & & & Loss: 8 words \\
\hline Recognition & $P C=0$ & $x$ & & & & & $\begin{array}{l}6 \text { Correct, } 9 \text { false } \\
\text { positives }\end{array}$ \\
\hline Logical memory I (WMS-R) & $P C=18$ & & $\mathbf{x}$ & & & & 21 Details \\
\hline Logical memory II (WMS-R) & $P C=0$ & $\mathbf{x}$ & & & & & $\begin{array}{l}2 \text { Details (after } \\
\text { request) }\end{array}$ \\
\hline \multicolumn{8}{|l|}{ Doors and people test } \\
\hline Doors test A (recognition) & 11 Out of 12 & & $\mathbf{x}$ & & & & \\
\hline \multicolumn{8}{|l|}{ Benton visual retention test } \\
\hline Free direct recall & 8 & & & & & & \\
\hline Number correct & 2 & & $\mathbf{x}$ & & & & $\begin{array}{l}\text { Expected number } \\
\text { correct: } 9\end{array}$ \\
\hline Number of errors & 0 & & $x$ & & & & $\begin{array}{l}\text { Expected number } \\
\text { errors: } 1\end{array}$ \\
\hline Free recall, delayed & 8 & $\mathbf{x}$ & & & & & $\begin{array}{l}\text { For delayed recall no } \\
\text { norms exist }\end{array}$ \\
\hline Delayed recall recognition & & & $\mathbf{x}$ & & & & \\
\hline \multicolumn{8}{|l|}{ Emotional story } \\
\hline Free recall (immediate) & 4 Details & & & & & & +1 Incorrect detail \\
\hline \multicolumn{8}{|l|}{ Recognition } \\
\hline Picture 1 & 5 Out of 7 & & & & & & \\
\hline Picture 2 & 3 Out of 7 & & & & & & \\
\hline Picture 3 & 3 Out of 7 & & & & & & \\
\hline Picture 4 & 7 Out of 7 & & & & & & \\
\hline Picture 5 & 3 Out of 7 & & & & & & \\
\hline Picture 6 & 3 Out of 7 & & & & & & \\
\hline Picture 7 & 3 Out of 7 & & & & & & \\
\hline Picture 8 & 3 Out of 7 & & & & & & \\
\hline Picture 9 & 3 Out of 7 & & & & & & \\
\hline Picture 10 & 1 Out of 7 & & & & & & \\
\hline Initial phase (pictures 1-4) & 18 Out of 28 & & & & & & $\begin{array}{l}\text { 64\% (Control group } \\
\text { [CG]: } 83 \% \text { ) }\end{array}$ \\
\hline Middle part (pictures 5-7) & 9 Out of 21 & & & & & & $\begin{array}{l}\text { 42.8\% (Emotional } \\
\text { part; CG: } 77 \% \text { ) }\end{array}$ \\
\hline
\end{tabular}




\section{Table 1 | Continued}

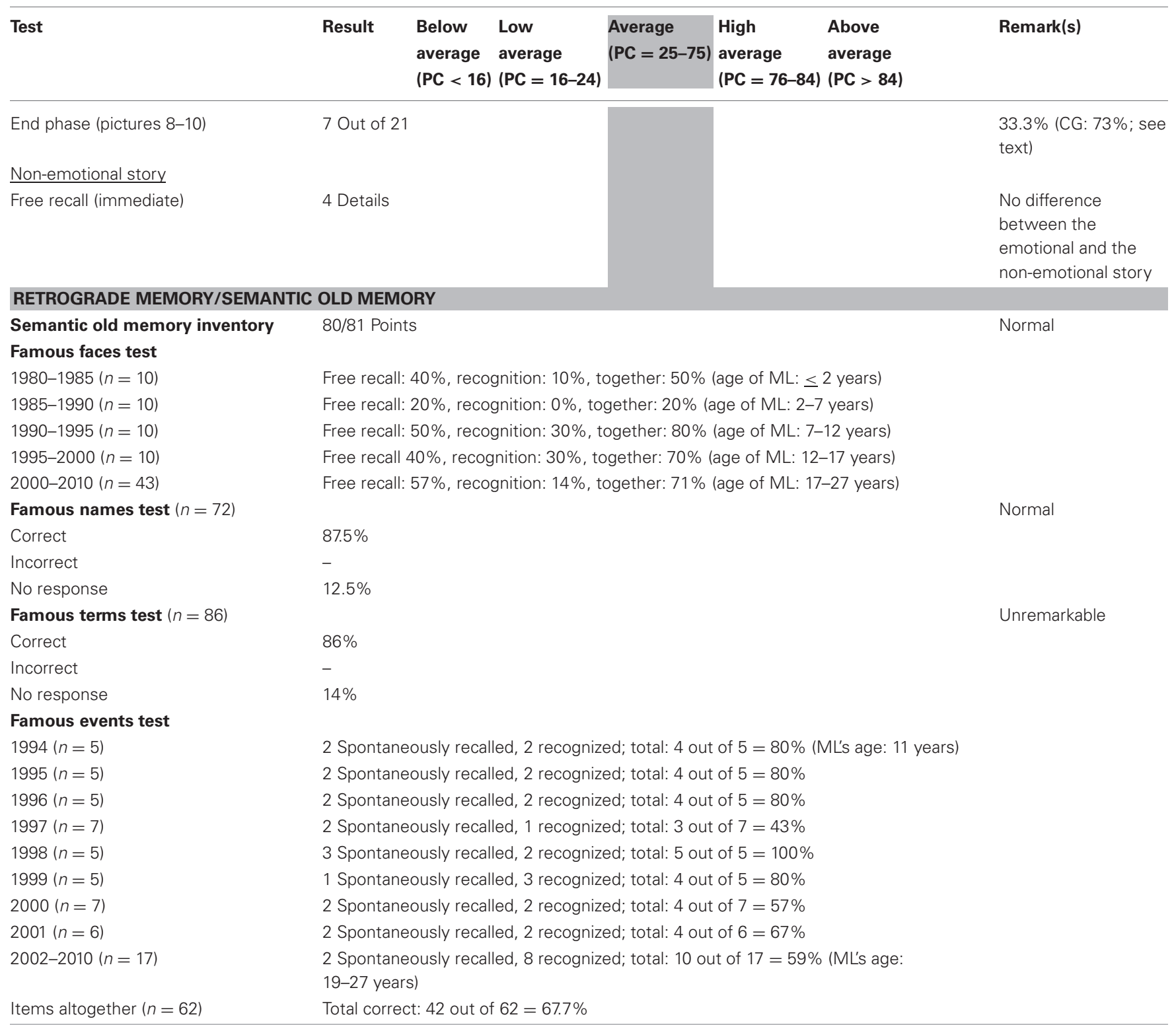

\section{RETROGRADE MEMORY/EPISODIC OLD MEMORY}

Autobiographic memory interview

\section{(AGI)}

Pre-school time

1. Autobiographical facts

2. Autobiographical recollections

Time period in basic school

1. Autobiographical facts

2. Autobiographical recollections

Later time in school/youth

1. Autobiographical facts

2. Autobiographical recollections
All existent

Tells anecdotes his mother had told him, but he himself has no autobiographical remembrances with a context of time, place, or emotion

All existent

Tells anecdotes, but remembers no autobiographical episodes

All existent

One highly emotional episode is remembered (he observed his father jumping out of the window after a fight with his mother) 
Table 1 | Continued

\begin{tabular}{|c|c|c|c|c|c|c|c|}
\hline Test & Result & $\begin{array}{l}\text { Below } \\
\text { average } \\
(\mathrm{PC}<16)\end{array}$ & $\begin{array}{l}\text { Low } \\
\text { average } \\
(P C=16-24)\end{array}$ & $\begin{array}{l}\text { Average } \\
(\mathrm{PC}=25-75)\end{array}$ & $\begin{array}{l}\text { High } \\
\text { average } \\
(P C=76-84)\end{array}$ & $\begin{array}{l}\text { Above } \\
\text { average } \\
(P C>84)\end{array}$ & Remark(s) \\
\hline
\end{tabular}

Early adulthood/present life

1. Autobiographical facts

All available

2. Autobiographical recollections

Even after repeated asking, no autobiographical remembrances with a context of time, place, or emotion

\section{PROCEDURAL MEMORY AND PRIMING}

\section{Mirror reading task}

1. Trial

Reading speed for procedural items

Reading speed for priming items

Reading speed for interference items

2. Trial

Reading speed for procedural items

Reading speed for priming items

Reading speed for interference items

Total scores (difference scores)

Procedural memory

Priming

Interference

Errors

1. Trial

2. Trial

PRIMING

Gollin incomplete figures

\section{PROSPECTIVE MEMORY}

Rivermead behavioral memory test

Grasshopper and Geese prospective

memory test

\section{ATTENTION/COGNITIVE PROCESSING SPEED}

\section{TMT-A}

Alertness (TAP 1 )

Without warning signal

With warning signal

Phasic alertness

\section{FWIT/CWIT}

\section{Color naming}

Color word reading

\section{ATTENTION/SELECTIVE ATTENTION}

\section{Go-no go ( $T A P^{\mathbf{1}}$ )}

Reaction speed

Omissions

Errors

\section{ATTENTION/DIVIDED ATTENTION}

\section{Divided attention (TAP ${ }^{\mathbf{1}}$ )}

\section{Reaction speed}

Omissions

Errors

$25 / 5 s$

$46 / 9.2 \mathrm{~s}$

$16 / 3.2 \mathrm{~s}$

$15 / 3 \mathrm{~s}$

$19 / 7.2 \mathrm{~s}$

$36 / 3.8 s$

$10 / 2 \mathrm{~s}$

$27 / 5.4 \mathrm{~s}$

0 Errors

$\mathrm{PC}=76$

$\mathrm{PC}=76$

$T=45$

$P C=42$

$P C>66$
Total reading time for all 10 words/average reading speed for 2 words (=1 card)

$-20 /-4 s$

2 Errors (1 priming word, 1 interference word)

1. Trial - average number of needed pictures: 6.3 out of 10

2. Trial - average number of needed pictures: 4.45 out of 10

Impaired; see text for details

Severely impaired; see text for details

$\mathrm{PC}=42$

$P C=62$

$T=44-45$

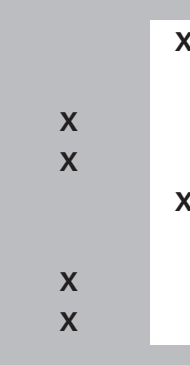

$\mathbf{X}$

$\mathbf{X}$
$\mathrm{PC}=46$
$\mathrm{PC}>40$
$\mathrm{PC}>38$

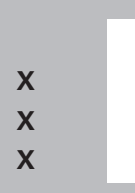

0 Omissions

0 Errors

$P C>66$
0 Omissions

0 Errors 
Table 1 | Continued

\begin{tabular}{|c|c|c|c|c|c|c|c|}
\hline Test & Result & $\begin{array}{l}\text { Below } \\
\text { average } \\
(\mathrm{PC}<16)\end{array}$ & $\begin{array}{l}\text { Low } \\
\text { average } \\
(P C=16-24)\end{array}$ & $\begin{array}{l}\text { Average } \\
(\mathrm{PC}=25-75)\end{array}$ & $\begin{array}{l}\text { High } \\
\text { average } \\
(P C=76-84)\end{array}$ & $\begin{array}{l}\text { Above } \\
\text { average } \\
(P C>84)\end{array}$ & Remark(s) \\
\hline
\end{tabular}

\section{ATTENTION/COGNITIVE FLEXIBILITY}

\section{TMT-B}

Attention switch (TAP 1 )

Reaction speed

$P C=82-84$

Errors

FWIT/CWIT

Interference trial

VISUO-CONSTRUCTIVE SKILLS

\section{Rey-Osterrieth figure}

Copy

$P C=58-62$

Mosaic test

score $=19$

\section{EXECUTIVE FUNCTIONS}

Word fluency

FAS-test

Verbal abstraction ability

$P C=12-13 \quad \mathbf{X}$

Finding of commonalities (HAWIE-R)

Score $=11$

Action planning

Tower of Hanoi

3 Disks

1. Trial

2. Trial

4 Disks

1. Trial

2. Trial

$\mathrm{PC}=84$

$P C<50$

$T=49$

Aborted

7 Steps

22 Steps

15 Steps

Burgau's little verbal planning test

Time needed and assistance

4/4 Points

Goal reached

4/4 Points

Problem solving/concept

comprehension

Mosaic test

wCST $^{2}$

Correct responses

Errors

Perseverations

California card sorting test

Number of sortings

Time
Score $=19$

36

0

0

8

$4 \mathrm{~min}, 20 \mathrm{~s}$ $\mathbf{x}$

$\mathbf{x}$

$\mathrm{x}$

3 Errors

$\mathrm{x}$

$\mathrm{x}$

Correct and detailed copy

No errors
Problem definition identified; analytic approach; no tendency towards errors; own errors recognized and thereafter immediate change of strategy

Autonomous start; action without assistance; time needed: $<5 \mathrm{~min}$ All errands correctly classified, 1 error which was corrected spontaneously

$\mathbf{X}$

X

No problems, understood the principle of the test even prior to starting with it

No problems, normal 
Table 1 | Continued

\begin{tabular}{|c|c|c|c|c|c|c|c|}
\hline Test & Result & $\begin{array}{l}\text { Below } \\
\text { average } \\
(\mathrm{PC}<16)\end{array}$ & $\begin{array}{l}\text { Low } \\
\text { average } \\
(P C=16-24)\end{array}$ & $\begin{array}{l}\text { Average } \\
(\mathrm{PC}=25-75)\end{array}$ & $\begin{array}{l}\text { High } \\
\text { average } \\
(\mathrm{PC}=76-84)\end{array}$ & $\begin{array}{l}\text { Above } \\
\text { average } \\
(\mathrm{PC}>84)\end{array}$ & Remark(s) \\
\hline \multicolumn{8}{|l|}{ Cronin-Golomb test } \\
\hline Abstract concepts & 5/8 Correct & & $\mathbf{x}$ & & & & \\
\hline Concrete concepts & 8/9 Correct & & & $x$ & & & \\
\hline $\mathrm{TkS}^{3}$ & 8/16 Points & $\mathbf{x}$ & & & & & \\
\hline Size & $4 / 4$ & & & & & & Impaired \\
\hline Weight & $1 / 4$ & & & & & & \\
\hline Number & $2 / 4$ & & & & & & \\
\hline Time & $1 / 4$ & & & & & & \\
\hline Safe decisions & 13 & & & $x$ & & & \\
\hline
\end{tabular}

SOCIAL INFORMATION PROCESSING TESTS: PERCEPTION OF EMOTIONAL AND COGNITIVE STATES, INTERPERSONAL SITUATIONS

Reading the mind in the eyes test $\quad 16 / 24$ Points $\quad X$

Multiple-Choice-ToM-Test (MCTT) 15/16 Points

Movie for the Assessment of Social

Cognition (MASC)

Correct

Exaggerated ToM

Reduced ToM

No ToM

Tübingen (Florida) affect battery

Faces subtests

\section{Face discrimination}

Affect discrimination

Affect naming

Affect selection

Affect matching

Prosody subtests

Discrimination of linguistic prosody

Discrimination of affective prosody

Affective prosody naming

Incongruent affective prosody

Congruent

Incongruent

Intermodal subtests

Matching of affective prosody to

emotional face expression

Matching of emotional face expressions $93.3 \%$

to affective prosody

PSYCHOPATHOLOGICAL AND PSYCHOLOGICAL LOAD SCREENINGTESTS/SCALES

BDI-II

4 Points
32

5

6

2

X

$100 \%$

$93.3 \%$

$86.6 \%$

$100 \%$

$86.6 \% \quad \mathbf{x}$

$100 \%$

$93.3 \%$

X

$86.6 \%$

$100 \%$

$84 \%$

X

X

X

X

X

$100 \%$

X
Low normal to

impaired $(M=19$,

$S D=2.7)$

Normal; 1 item "too positive"

Slightly impaired
Comparison scores,

healthy $\mathrm{Ss}^{4}(n=12)$

$M=98.8, S D=2.7$

$M=91.6, S D=5.6$

$M=94.8, S D=5.6$

$M=96.5, S D=3.7$

$M=94.3, S D=5.3$

$M=100, S D=0$

$M=100, S D=0$

$M=94.9, S D=7.6$

$M=98.0, S D=4.7$

$M=94.1, S D=6.2$

$M=95.5, S D=6.6$

$M=97.7, S D=3.4$

No hint of

depressive

symptomatology 
Table 1 | Continued

\begin{tabular}{|c|c|c|c|c|c|c|c|}
\hline Test & Result & $\begin{array}{l}\text { Below } \\
\text { average } \\
(\mathrm{PC}<16)\end{array}$ & $\begin{array}{l}\text { Low } \\
\text { average } \\
(P C=16-24)\end{array}$ & $\begin{array}{l}\text { Average } \\
(\mathrm{PC}=25-75)\end{array}$ & $\begin{array}{l}\text { High } \\
\text { average } \\
(P C=76-84)\end{array}$ & $\begin{array}{l}\text { Above } \\
\text { average } \\
(P C>84)\end{array}$ & Remark(s) \\
\hline
\end{tabular}

\section{SCL-R}

Scales

Somatization

$T=35 \quad \mathbf{X}$

Obsessive-compulsiveness

$T=48$

$T=36$

X

Interpersonal sensitivity

$T=48$

$T=39$

X

Anxiety

$T=40$

$T=45$

$T=40$

$T=42$

Psychoticism

Global Indices

GSI (global severity index)

$T=35 \quad \mathbf{X}$

PSDI (positive symptom distress index)

$T=39$

$T=37$

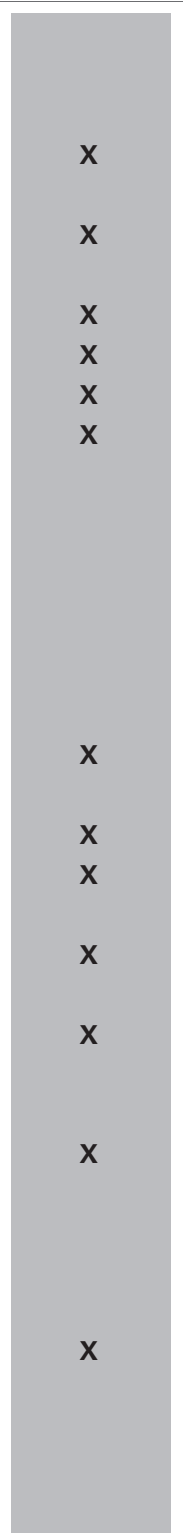

Stanine $=1 \quad \mathbf{X}$

Stanine $=4$

Stanine $=3$

Stanine $=6$

Stanine $=4$

Stanine $=2 \quad \mathbf{X}$

Stanine $=4$

Stanine $=2 \quad \mathbf{X}$

Physical complaints

Stanine $=4$

Stanine $=2 \quad \mathbf{X}$

Stanine $=2 \quad \mathbf{X}$

Stanine $=4$

\section{X}

$\begin{array}{ll}\mathrm{PR}=14 & \mathbf{X} \\ \mathrm{PR}=40 & \\ \mathrm{PR}=12 & \mathbf{X} \\ \mathrm{PR}=8 & \mathbf{X}\end{array}$

EWL-N (Personal adjectives list) AUTISM/EMPATHY SCALES

Autism-spectrum-quotient

Cambridge Behaviour Scale

(empathy-quotient)

\section{Saarbrücken personality}

questionnaire (interpersonal

reactivity index)

$\underline{\text { Scales }}$

Empathy

Phantasy
Score $=96$

$$
\mathrm{AQ}=15
$$$$
\mathrm{EQ}=53
$$

Score $=90$
See text

$M=16.4 ;$ no indices for autistic tendencies High average (males: $M=41.8, S D=11.2)$

$M=100, S D=10$ 


\section{Table 1 | Continued}

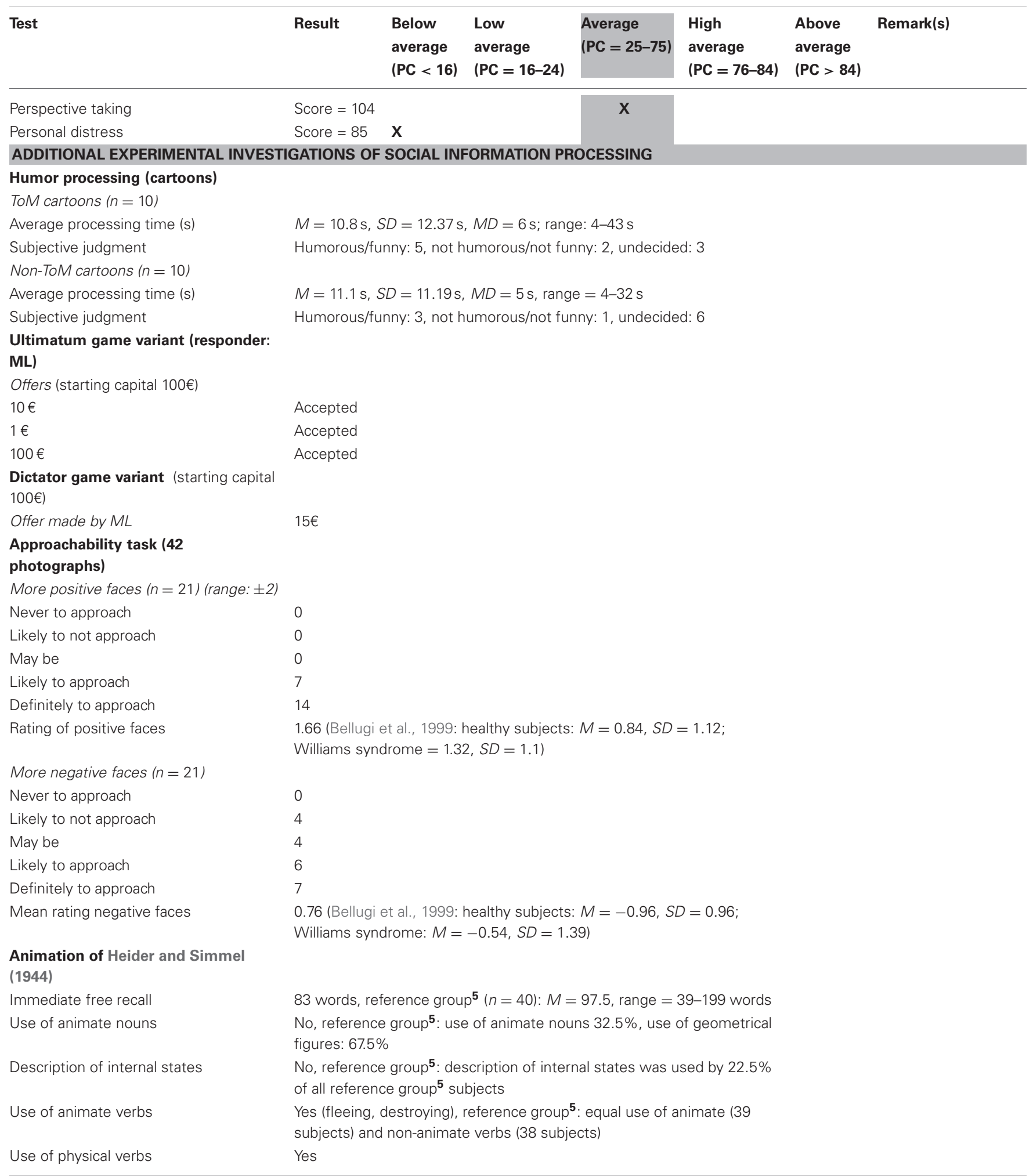


Table 1 | Continued

\begin{tabular}{|c|c|c|c|c|c|c|c|}
\hline Test & Result & $\begin{array}{l}\text { Below } \\
\text { average } \\
(\mathrm{PC}<16)\end{array}$ & $\begin{array}{l}\text { Low } \\
\text { average } \\
\text { (PC = 16-24) }\end{array}$ & $\begin{array}{l}\text { Average } \\
(P C=25-75)\end{array}$ & $\begin{array}{l}\text { High } \\
\text { average } \\
(P C=76-84)\end{array}$ & $\begin{array}{l}\text { Above } \\
\text { average } \\
(\mathrm{PC}>84)\end{array}$ & Remark(s) \\
\hline \multicolumn{8}{|l|}{ MALINGERINGTENDENCIES ${ }^{6} /$ EFFORT } \\
\hline Rey-memory-test & 11 Out of 15 & & & $\mathbf{X}$ & & & Cut-off: 8 \\
\hline Bremen auditory memory test ${ }^{7}$ & 8 Out of 15 & $\mathbf{X}$ & & & & & Cut-off: 12 \\
\hline $\begin{array}{l}\text { Test for assessing memory ability in } \\
\text { everyday life }\end{array}$ & 11 Out of 15 & & $\mathbf{X}$ & & & & Cut-off: 12 \\
\hline
\end{tabular}

1 TAP, Testbatterie zur Aufmerksamkeitsprüfung (Test Battery for the Assessment of Attention).

${ }^{2}$ WCST Wisconsin Card Sorting Test.

${ }^{3}$ TkS, Test für kognitives Schätzen (Test of Cognitive Estimation).

${ }^{4}$ Ss, subjects (Breitenstein et al., 1996)

${ }^{5}$ Replication study: Curci-Marino et al. (2004).

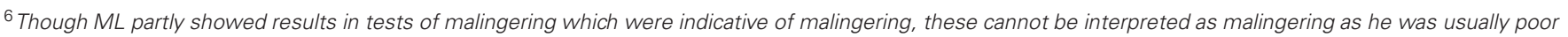
in memory recall in general.

${ }^{7}$ Bremer Auditiver Gedächtnistest.

${ }^{8}$ Test zur Überprüfung der Gedächtnisfähigkeit im Alltag.

A T-score is a standard score that sets the mean to fifty and standard deviation to 10.

A percentile $(P C)$ is the value of a variable below which a certain percent of observation fall.

Stanines are standard scores with a maximum of 9. Stanines 1-2 and 8-9 indicate significant deviations from normative data.

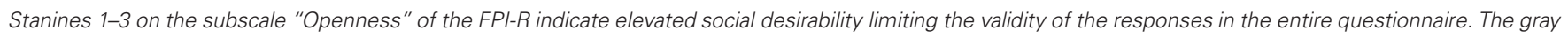
column in the middle reflects average or normal scores.

the lateral ventricles and of the external cerebrospinal fluid space (increased sulcal cerebrospinal fluid). Hippocampal changes were not described and no comment was made about the significance of the enlargement of the lateral ventricles.

Over the years ML attended several therapies and he graduated from a special needs school. ML completed 10 years of schooling, repeating one school year. His school trajectory might therefore seem different than that of other patients with developmental amnesia described in the literature, who were reported to have attended mainstream schools ("albeit with considerable difficulties in some cases”) (Gadian et al., 2000, p. 505) (but, see also Bindschaedler et al., 2011). Incidentally, Picard et al. (2012) recently published two case reports of patients whom they diagnosed with developmental amnesia. One of those patients showed an atypical schooling pathway; she failed normal schooling and similarly to ML, she subsequently attended specialized school.

Since age $20 \mathrm{ML}$ has received external help from a caretaker regarding planning, remembering important appointment dates, and managing finances. He has lived in a supervised setting since finishing school. ML's living situation again points to a difference between ML and other cases of developmental amnesia (Rabin et al., 2012). However it is worth mentioning that other patients with diagnoses of developmental amnesia were described to live in "protective environments" (though not in residential settings) (Picard et al., 2012). In contrast to his everyday memory impairments, ML has shown impressive special knowledge in some fields, which he has no problem to acquire and retrieve. He for example, has a very broad and detailed knowledge of special luxury goods such as watches and car brands. Furthermore, he can learn and remember very well pieces of music. ML joined a dance course 4 years prior to his assessment in our clinic. His substitute decision maker states that ML is a very good dancer and has an incredible ability to learn new forms of dancing. Similarly to other patients with amnesia after adult or early-onset hippocampal damage (Milner et al., 1968; Rabin et al., 2012), ML is aware of his memory impairment; he has learned to partially compensate for it by using strategies such as repetition and reliance on calendars to keep track of scheduled appointments.

On an interpersonal level ML's ability to interact with his peers has significantly improved since his school years. His substitute decision maker however voiced concerns about ML's heightened capacity to trust other people. In spite of being repeatedly told not to give money to other people (and carrying in his portemonnaie a visible note stating that), ML has continued to lend money to people without usually getting it back.

\section{IMAGING FINDINGS}

ML underwent several structural MRI at different locations. The most recent imaging was performed when ML was age 29 years, with a 3-Tesla MRI scanner (Siemens Magneto Verio whole-body MRI system equipped with a head volume coil). The procedure was undergone in a neuroradiological center specialized for assessing patients with epilepsy pre- and post-operatively. The imaging data were evaluated by a neurologist with expertise in neuroradiology (Friedrich G. Woermann). Visual inspection revealed grossly reduced (gray matter) density within hippocampi bilaterally (Figures 1 and 2). There was no evidence of pathology in the underlying parahippocampal region or other brain regions based on visual inspection. Using voxel-based morphometry (VBM; SPM8, Wellcome Institute, London, UK), a quantitative comparison of 3D T1-weighted images of patient ML with 10 age-matched healthy control participants was performed (for details regarding 
the method employed here, please refer to Labudda et al., 2012). The hypothesis-driven comparison within a hippocampal volume of interest demonstrated a marked reduction of gray matter volume within both hippocampi of the patient ML $[p<0.05$, Familywise Error (FWE)], with an anterior and right-sided preponderance. Only when using a whole brain analysis with a less conservative statistical threshold ( $p<0.001$, uncorrected), we

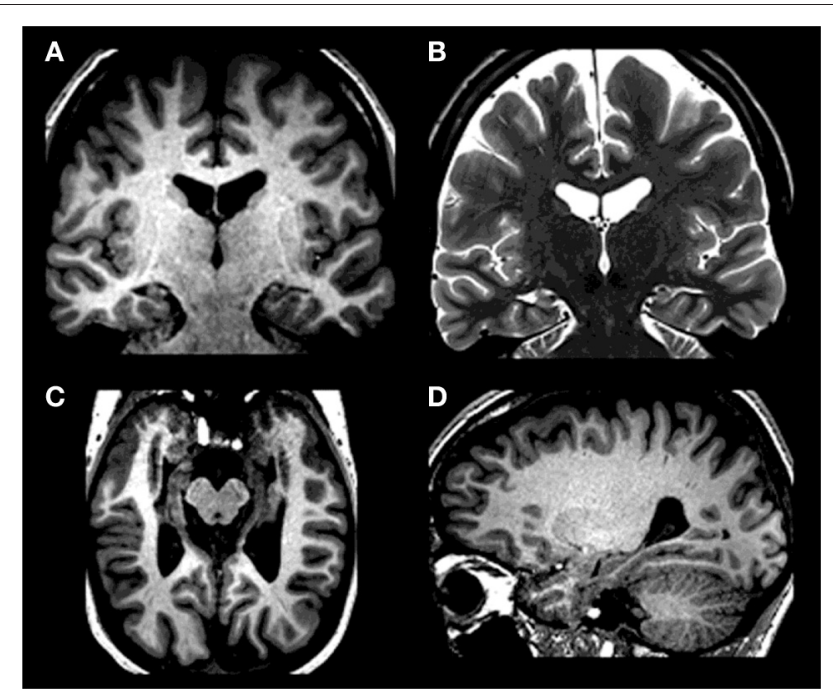

FIGURE 1 | Bilateral hippocampal atrophy in ML with T1-weighted images [(A) coronal; (C) axial; (D) sagittal] demonstrating reduced hippocampal size in all directions - in the absence of marked extrahippocampal atrophy; T2 weighted coronal image (B) demonstrating bilateral loss of internal structure - here: a further marker of bilateral hippocampal atrophy. On clinical MRIs left side of the image is right side of the patient. evidenced indices of further reductions of gray matter, affecting both amygdalae and basal ganglia (striatum, pallidum) - with a right-sided preponderance as well and pulvinar (bilaterally, but with a right-sided trend).

\section{TESTS}

\section{NEUROPSYCHOLOGICAL ASSESSMENT}

The following tests were administered:

- Standardized tests for handedness and brain lateralization The Lateral Preference Inventory (LPI) for measurement of handedness, footedness, earedness, and eyedness (Ehrenstein and Arnold-Schulz-Gahmen, 1997), and the Questionnaire for measuring motor asymmetry (Reiss and Reiss, 2000). This last test contains 12 queries for assessing handedness and footedness.

- Standardized tests for the estimation of intelligence and overall cognitive status

Abbreviated Wechsler Adult Intelligence Test-Revised (Block test and Picture Completion test) (Dahl, 1972). MWT-B or Mehrfachwahl-Wortschatz-Intelligenztest-B (Lehrl, 2005), a German version of the National Adult Reading Test NART (Nelson, 1982). The reasoning and rule recognition subtest from Leistungsprüfungssystem (LPS-4; Horn, 1983). The Mosaic Test from the revised Hamburg Wechsler Intelligence Test (HAWIER; Tewes, 1991), a German-language adaptation of the Wechsler Intelligence Test for Adults-Revised (WAIS-R) (Wechsler, 1981). Matrices Test from Wechsler Intelligence test for Adults (Aster et al., 2006). Commonalities finding test from HAWIE-R (Tewes, 1991).

- Standardized tests for the evaluation of attention, concentration, and processing speed

Trail Making Test A and B (TMT-A + TMT-B; Lezak, 1995; Reitan, 1958); Attention Index of the German version of the Wechsler Memory Scale-Revised (WMS-R; Härting et al., 2000);

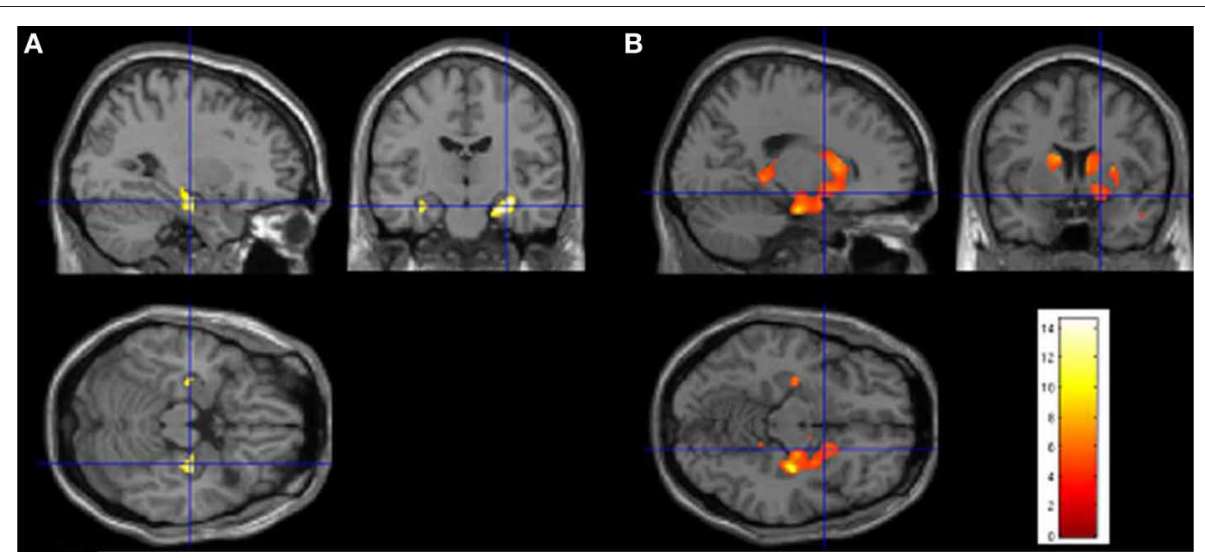

FIGURE 2 | Quantitative comparison of 3D T1-weighted images of patient ML with 10 age-matched control subjects using voxel-based morphometry (VBM; SPM8, Wellcome Institute, London, UK). For details regarding the method used here, please refer to Labudda et al. (2012). (A) Hypothesis-driven comparison within a hippocampal volume of interest demonstrates a marked reduction of gray matter volume within both hippocampi of the patient $(p<0.05$, FWE) which has an anterior and right-sided preponderance (please note that in SPM the right side of the picture is the right side of the patient - see crosshair). (B) Using a whole brain analysis with a less conservative statistical threshold ( $p<0.001$, uncorrected), there are further reductions of gray matter, affecting amygdalae (bilaterally), bilateral dorsal striatum (mainly caudate and putamen, and to a certain extent the globus pallidus), portions of the ventral striatum (bilaterally), and posterior portions of the pulvinaris complex (also bilaterally), again with a right-sided preponderance. 
the subtests Alertness, Selective Attention, and Divided Attention of the Test Battery for the Assessment of Attention or Testbatterie zur Aufmerksamkeitsprüfung (TAP) (Fimm and Zimmermann, 2001). The TAP is a computer-based test that assesses attentional performance based on reaction times. The Alertness subtest provides a measure of general slowing. The Selective Attention subtest is a go/no-go task, during which the participant has to selectively react to a group of stimuli, but not to others, and to inhibit a dominant response. The Divided Attention subtest is a "dual task" paradigm that assesses the ability to flexibly switch attention between two ongoing tasks (Fujiwara et al., 2008).

- Standardized tests for evaluation of short-term memory and working memory

Wechsler Memory Scale-Revised; digit span and block span forward and backward; adaptive digit ordering test (Hoppe et al., 2000). In this last test digits which are presented in random order have to be recalled in ascending order (e.g., 4-3-9-3 should be recalled as 3-3-4-9).

- Standardized tests for the evaluation of constructional functions and planning

Copy administration of the Rey-Osterrieth Figure Test (Osterrieth, 1944; Lezak, 1995); Benton Visual Retention Test (Lezak, 1995; Spreen and Strauss, 1998); Burgau Little Verbal Planning Test (Burgauer Kleiner Verbaler Planungstest; von Cramon and Zihl, 2012); Test of Cognitive Estimation (TkS; Brand et al., 2002, 2003a,b). The Benton Visual Retention Test taps on many different abilities such as visuo-spatial perception, visual and verbal conceptualizations, and working memory at the border to long-term memory. The Burgau Test requires the planning of a time-based sequence in which several transactions (going shopping) have to be organized within a given time. The $\mathrm{TkS}$ is a German-language test for cognitive estimation (Shallice and Evans, 1978), during which participants are requested to estimate numbers, weights, heights/lengths, and time durations.

- Standardized tests for the evaluation of the verbal and non-verbal explicit anterograde long-term memory

Wechsler Memory Scale-Revised (Härting et al., 2000); Verbal Learning Memory Test (VLMT) (Helmstaedter et al., 2001); Rey-Osterrieth Figure; Copy trial followed by delayed recall after 30 min (Lezak, 1995); the Doors Test (visual recognition) of the Doors and People Test (Baddeley et al., 1994; Adlam et al., 2009); Rivermead Behavioral Memory Test (Wilson et al., 1985). The VLMT requires the recall of a list A of 15 presented words for 5 trials, the recall of a second (interference) list $\mathrm{B}$, then again recall of the list A, and recall of it after $30 \mathrm{~min}$ delay, and finally the recognition of words of list A from words belonging to lists A and B and to none of the two. The Doors test requires the visual recognition of 12 easily and 12 difficultly to discriminate doors, each from an array of 4 doors. And the RBMT contains a number of subtests assessing retrospective and prospective visual and verbal memory functions.

- Tests for the evaluation of retrograde memory (standardized or qualitative)

Semantic Knowledge Test [Semantic Old Memory Inventory; Schmidtke and Vollmer-Schmolck, 1999 (qualitative description)]; Bielefeld Autobiographical Memory Interview (BAGI; standardized; partly based on the Autobiographical Memory
Interview of Kopelman et al., 1990; Fujiwara, 2004; Fujiwara et al., 2008; Fast et al., 2013; Famous Faces Test; standardized; see Jänicke, 2001), Famous Terms, Famous Events and Famous Names Tests [(qualitative descriptions); Leplow and Dierks, 1997; Markowitsch, 2003; Fujiwara et al., 2008]. In the Semantic Knowledge Test general facts are asked ("What is the currency in Switzerland?"), in the BAGI two episodes with time, place, emotional involvement are requested from all periods of the past life, divided into 5- or 10-year epochs.

- Test for evaluation of prospective memory - qualitative description (Knight et al., 2010; Staniloiu and Markowitsch, 2012).

Recalling to perform an intended future action, in particular to ask at the end of the testing for a personal object that the examiner had borrowed from the patient and hid in the examining room, in response to a pre-specified cue, namely the end of the testing. "The Grasshoppers and Geese Prospective Memory Test" (Lanting et al., 2010, 2011), which was developed for ethnically diverse individuals, comprises a task instruction that is embedded semantically. The test requests that the patient reminds the examiner to perform a task when an external (verbal) cue is delivered. If the patient does not respond to the cue, a series of three verbal prompts are provided. Scores range from 0 (no prompts required) to 4 (no recall to perform the action after all three prompts).

- Tests for the evaluation of priming (standardized) and procedural memory (qualitative description)

Mirror Reading Test (von Cramon et al., 1993; Borsutzky et al., 2008, 2010), Gollin Incomplete Pictures Test (Gollin, 1960; Markowitsch et al., 1993; von Cramon et al., 1993).

For the Mirror Reading Test the version that is described in Borsutzky et al. $(2008,2010)$ was used. This variant allows a differentiation between priming and procedural memory. It comprises a series of 15 cards each consisting of two German words in mirror writing ( 30 words in total, all words with 8 to 10 letters) which are visually presented to the participants. Participants are asked to read the words as quickly and accurately as possible. Upon correct reading of the two words of one card, the next card is presented. The time by which subjects read both words correctly, constitutes the reading time measure. If they read a word incorrectly, they are told so. However, the correct word is not provided. In addition, all incorrect responses are counted. After a delay of $30 \mathrm{~min}$ a surprise second trial is administered. Herein, 10 words (on five cards) are identical with the first trial, 10 words are new and 10 words are also new, but similar in orthography to 10 words of trial 1 (e.g., "Explosion" and "Exkursion"). The sequence of cards is randomized for both trials. Improvement in reading speed from trial 1 to trial 2 of the recurring words serves to measure priming performance ("Priming"). Improvement in reading time of new words is used for an index of skill acquisition, i.e., procedural learning ("Procedural Memory"). Those words of trial 2 that are orthographically similar to words of trial 1 ("Interference") are created to induce interference in reading. We assume that due to these similarities in orthography with the words of trial 1, subjects might be disturbed in automatic reading processes. In trial 2 participants may initially tend to recognize the similarly looking words of trial 1 due to priming effects, but during reading, 
they would notice most discrepancies and would then have to execute a more effortful analysis. On the one hand, this may lead to longer reading times. On the other hand, if subjects experience deficits in suppressing the activated, but irrelevant memory trace (i.e., the "Interference" words of trial 1), they may produce more mistakes in reading of "Interference" words in trial 2 compared to "Priming" and "Procedural Memory" items.

In the Gollin Incomplete Pictures Test 20 pictures are presented, each picture containing a single familiar item (tree, ship, rabbit, etc.). Each item is given in 10 versions from a barely suggestive drawing (just a few dots or line drawings) to complete figure drawing. The participant has to tell what he or she thinks is to be seen in the drawing. Usually healthy participants recognize the item between versions 5 and 6 , when given the first time, but much earlier (version 2 or 3 ), when it is given the second time.

- Tests for the assessment of executive functions, problem solving, and cognitive flexibility

Trail Making Test-B (Lezak, 1995); Tower of Hanoi (Borys et al., 1982; Spitz et al., 1982; Lezak, 1995); California Card Sorting Test (Delis et al., 1987, 1992); problem solving test of Cronin-Golomb et al. (1987a,b); Wisconsin Card Sorting Test (Nelson, 1976); Game of Dice Task (Brand et al., 2005; Brand and Markowitsch, 2010). (All tests but the problem solving test of Cronin-Golomb are standardized.) In the problem solving test participants are given 17 sheets of paper, one after another; each sheet shows a drawing on the left side of the paper and three drawings on the right side (e.g., a crescent moon on the left side and a penguin, a woodpecker, and an owl on the right side). The participant should tell which of the three drawings on the right side best matches the drawing on the left side; we provide a qualitative description of performance on this test.

The Game of Dice Task is presented via computer. It is a fictitious gambling situation with explicit rules for virtual gains, losses, and winning strategies, which assesses decision-making under risk. A virtual single dice and a shaker are employed. Before throwing the virtual dice for 18 times, participants each time have to choose a single or a combination of 2, 3, or 4 numbers. Each choice is associated with different gains or losses. Participants get visual and acoustic feedback for their former decision.

\section{- Standardized tests of verbal fluency}

Controlled Oral Word Association Test [COW fluency tasks (FAS); Golden et al., 2002]; Supermarket task (word production) (Calabrese and Kessler, 2000); Boston Naming Test (Kaplan et al., 1983; Lezak, 1995; Spreen and Strauss, 1998; Golden et al., 2002); the German version of the Stroop Test (Farbe-Wort-Interferenz Test/FWIT; or CWIT for Color Word Interference Test; Stroop, 1935; Bäumler, 1985).

- Standardized tests for calculation

Zahlenverarbeitungs- und Rechentest (ZRT; Kalbe et al., 2002). In this test various simple and more complex calculations have to be done (additions, subtractions, multiplications, divisions).

- Standardized tests for evaluation of malingering tendencies Tests of memory malingering/effort [Rey 15-Item-Test (Lezak, 1995); tests from the Test Battery for Forensic Neuropsychology
(TBFN; Bremer Auditory Memory Test; Test for Assessing Memory Ability in Everyday Life) (Heubrock and Petermann, 2000)]. In the TBFN subjects listen to a number of sounds (e.g., cackling of geese, honking) and later have to name them, or they listen to statements and later get for each statement a choice of four alternatives what was said (e.g., whether a meeting was at $10,12,2$, or 4 o'clock).

- Tests for evaluation of emotional processing

Florida Affect Battery (translated as Tübingen Affect Battery; Bowers et al., 1991; Breitenstein et al., 1996; standardized test); Emotional Pictures Test (von Cramon et al., 1993; performance on this test was qualitatively compared with the performance of the healthy control group and patient $\mathrm{HI}$ with septal nuclei damage described in von Cramon et al., 1993); Picture Story for Affect Induction (BAd; Temizyürek, 2003; qualitative description); Interpersonal Reactivity Index (Saarbrücker Persönlichkeitsfragebogen/Saarbrücken Personality Questionnaire; standardized; Beven et al., 2004; Paulus, 2012). In the Emotional Pictures Test 40 photographs with scenes of a neutral, positive, or negative content (e.g., shooting at a person, kissing another person) are presented and after half an hour the 40 original pictures had to be recognized out of 80 photographs. Control healthy participants (von Cramon et al., 1993) performed at a level of $95 \%$ correct for emotional and $88.3 \%$ correct for neutral pictures in the Emotional Pictures Test.

In the BAd two versions of a story about a family (mother, father, child) are shown - in the neutral version a day in their life is shown in pictures without that the child is involved in a car accident; in the emotional version the child is involved in a car accident. While watching the pictures the participant also listens to a male voice providing a narrative for each picture. The two variants of the story are identical for the first and last third of the pictures, but differ for the second third.

- Standardized tests for mood, personality and psychopathological, and psychological load screening

Beck Depression Interview-II (BDI-II; Hautzinger et al., 2006); The Symptom Checklist Revised or SCL-90R (Hessel et al., 2001); Freiburg-Personality-Inventory-Revised (FPI-R; Fahrenberg et al., 2001); The German version of the TorontoAlexithymia-Scale (Kupfer et al., 2001); Autism-SpectrumQuotient (Baron-Cohen et al., 2006); Cambridge Behavior Scale (de Haen, 2006); Eigenschaftswörterliste EWL-N (List of personal adjectives) (Janke and Debus, 1978). The SCL90R assesses psychiatric symptom load and psychological distress. It has nine subscales, such as somatization, obsessivecompulsiveness, interpersonal sensitivity, depression, anxiety, anger-hostility, phobic anxiety, paranoid thinking, and psychoticism. The general psychological distress level is estimated based on a global severity index, which is derived from all subscales. The FPI-R provides an assessment of personality along 12 dimensions: life satisfaction, social orientation, motivation to achieve, inhibition, excitability, aggressiveness, stress, physical complaints, health worries, openness, extraversion, and neuroticism. The EWL-N is a multidimensional self-administered scale, describing the actual well-being. It contains 15 subscales, 
assessing activity, concentration, passivity, fatigue, extraversion, introversion, self-confidence, mood elevation, excitability, interpersonal sensitivity, irritability, anxiety, depressive tendency, dreaminess, and numbness. The scale was given to both ML and his mother who were both requested to choose the personal adjectives that matched ML's characteristics best.

- Standardized test for visual perception Judgment of Line Orientation (Lezak, 1995; Mitrushina et al., 2005).

- Tests for social information processing

Tests for social perception (perception of face, speech perception) “Tübinger Affekt Batterie," a German-language version of the Florida Affect Battery (Bowers et al., 1991; Breitenstein et al., 1996) was administered.

\section{Tests for social cognition (theory of mind, empathy)}

"Augen-ToM-Test," a 24 photographs containing German adaptation of the well-known RMET (Baron-Cohen et al., 2001; Fleck et al., 2002; Reinhold and Markowitsch, 2007; Fujiwara et al., 2008) was administered (for a detailed description of the version of this test, see Dziobek et al., 2006). During the task only the eye regions of female (12) and male (12) faces are presented. The participant has to choose one of the four verbal descriptors (words) that she or he thinks it describes the best the mental state of the character. For a comparison group, we referred to age and educational matched data from Reinhold and Markowitsch (2007) and Dziobek et al. (2006). Mean scores and standard deviations are presented in Table 1.

The Multiple-Choice-ToM-Test (MCTT; Kalbe et al., 2001; Adenauer et al., 2005) version that we used requires the participants to read 16 short stories. (The test exists in two versions, one with 30 short written stories and another one with 16 stories. We provide a qualitative description of the performance on the abbreviated version of the MCTT). After each story (see example below) the participant has to make inferences about the mental states of a character of the story by resorting to a forced multiple choice format with four possible answers (only one right answer). The multiple choice format enables differentiation of three different types of mistakes: (a) mental states inferences that are "excessive"; (b) mental state inferences that are "too positive"; (c) choice of the distractor answer that reflects a neutral answer (i.e., a non-mental state inference such as physical causation).

Example of a story from MCTT:

Die Bananenschale (The banana skin; translated from German):

Joseph slips on the footpath on a banana skin and falls down. A woman close to him starts to laugh loudly. What does Joseph think?

(1) Such a silly woman. She should keep her mouth shut.

(2) Well, she is in a good mood.

(3) She definitely smashed the banana skin purposefully to this place.

(4) The woman wears a nice skirt.

The movie for the assessment of Social Cognition (MASC) (Dziobek et al., 2006; Fleck, 2008) requires the participants to watch a video about four individuals in their mid-thirties who gather for a dinner party. The movie is $15 \mathrm{~min}$ long, but it is paused and the participants have to answer questions concerning the film characters' emotions, thoughts and intentions. Therefore the test session lasts around $45 \mathrm{~min}$. The test has been applied to healthy participants, patients with Asperger syndrome (see Dziobek et al., 2006) and patients with schizophrenia (Fleck, 2008). For comparison groups, we referred to the study of Dziobek et al. (2006). Mean scores and standard deviations are presented in Table $\mathbf{1}$.

The animation of Heider and Simmel (1944); Lück (2006), and Curci-Marino et al. (2004). The animated and silent short movie created by Heider and Simmel shows three geometrical figures (a large triangle, a small triangle and a small circle), which are moving in the neighborhood of a rectangle. In our study, we used a procedure similar to that of Curci-Marino et al. (2004), who applied this test to 40 German-speaking participants (15 women and 25 men) recruited from a technical university with a mean age of 24.3 years, in an attempt to replicate the original results of Heider and Simmel (1944). The movie was shown twice on a computer screen. As Heider and Simmel, we used a general task, such as "describe in writing what you saw in the movie." The text produced by the participant was then analyzed in a manner similar to that of Curci-Marino and colleagues and the results were qualitatively compared to those obtained by CurciMarino and colleagues. We recorded the number of total words used and analyzed the use of animate nouns versus nouns designing geometrical figures, the description of internal states, the use of physical verbs versus animate verbs.

Understanding humor (Happé et al., 1999; Shammi and Stuss, 1999; Stuss and Levine, 2002; Uekermann et al., 2006; Bodden et al., 2010a) was qualitatively investigated. In the Humor task that we used, the participant is shown 20 cartoons from popular magazines. Similarly to the design of Happe et al. (1999), the cartoons are grouped in two conditions: 10 ToM cartoons and 10 non-mentalistic cartoons (the latter involved a physical anomaly). Cartoons are randomly shown, one at a time, on a computer screen. The participant is told to look at each cartoon and announce when he understood the joke. He then is asked to try to explain to the experimenter why each cartoon is funny. In addition to providing an explanation, the participant is asked to provide a subjective funniness rating for each cartoon. The mean times needed for processing the ToM cartoons and non-ToM cartoons are recorded (Bodden et al., 2010a).

\section{Tests for social cognition (social judgment)}

The Approachability Task (Adolphs et al., 1998) assesses the ability to make social judgments of other people. For this study we used an adaptation of the original task of Adolphs et al. (1998), which had been employed by Bellugi et al. (1999) to test 26 participants with Williams syndrome (WMS; mean age 23.6) and 26 healthy participants of similar age and gender ratio (mean age 25.5). Similarly to Bellugi et al. (1999) we used 42 black and white photographs of unfamiliar human faces, which were taken out of a pool of 100 original stimuli (Adolphs et al., 1998); 21 of these photographs depicted faces for which normal controls had given more negative ratings and 21 showed faces for which normal controls had given more positive ratings. The photographs were shown to ML one at 
a time, in random order. Without time constraints, ML had to rate the approachability of the face stimulus on a five point Likert type scale, which ranged from -2 (very unapproachable) to +2 (very approachable), by indicating how much he would approach and strike up a conversation on a street with the person whose face was depicted in the photograph. ML's performance was qualitatively compared to the results of Bellugi et al. (1999).

\section{Tests for social cognition (moral judgment)}

We used variations of the Ultimatum and Dictator Games which deviated from standard tests in several respects (Koenigs and Tranel, 2007). In the Ultimatum Game, ML acted as the responder. The starting capital was 100 Euros (Bolton and Ockenfels, 1998; Vieth, 2003; Oosterbeek et al., 2004). However, in contrast to the standard Ultimatum Game, participation was at the end of the experiment compensated with a fixed amount regardless of responses on the task (Koenigs and Tranel, 2007). Furthermore, in this variation, the examiner knew the proposers' identity and the offers were predetermined by the experimenter (Koenigs and Tranel, 2007). In the variation of the Ultimatum Game we used, the starting capital was 100 Euros; again, a fixed compensation at the end of the experiment regardless of responses on the task was offered. ML acted as dictator, deciding how much of the capital to keep. Again, the examiner knew both the identity of the "dictator" and "recipient."

\section{Tests for social regulation (cognitive control, emotion regulation,} monitoring/error correction, deception)

Game of Dice Test (Brand et al., 2005; Brand and Markowitsch, 2010); Interpersonal Reactivity Index (Saarbrücker Persönlichkeitsfragebogen/Saarbrücken Personality Questionnaire; Beven et al., 2004; Paulus, 2012); tests for evaluation of malingering tendencies (see above). The Game of Dice Task was described above under tests for executive functions. The personal distress scale of the Saarbrücken Personality Questionnaire contains queries which tap on emotional regulation.

Prior to starting the testing process, Mr. N. was asked a series of general interview questions, to assess for problems with awareness and orientation.

\section{TESTING RESULTS AND INTERPRETATION GENERAL BEHAVIORAL OBSERVATIONS}

ML came to the assessment accompanied by his surrogate decision maker. Informed written consent was obtained for the participation in the study and publication of the report. The study adhered to the declaration of Helsinki.

ML was eager to participate and to show what he is able to do. In the following we will describe results from testing him over a period of about $8 \mathrm{~h}$ (with breaks). A summary of ML's testing results is provided in Table 1.

\section{LATERALITY}

ML in general was lateralized to the right, though he used his left hand for writing and other ways of motor performance (Laterality Preference Inventory). In the Questionnaire for Measuring Motor Asymmetry he provided evidence for a symmetrical foot use and more frequent use of his left hand.

\section{LANGUAGE AND WORD KNOWLEDGE}

ML's knowledge of terms and words was good (Boston Naming Test). He just failed to name asparagus and did not know the exact terms for yoke and abacus.

\section{VISUAL PERCEPTION}

Visual perception, as tested with the Line Orientation Test, was within normal limits.

\section{ATTENTION, CONCENTRATION, AND PROCESSING SPEED}

In all test of attention, concentration, and processing speed ML gained at least within normal limits situated scores. In the Trail Making Test $A$ and $B$ his performance was above average; testing results for reaction speed and phasic alertness were indicative of above average performance as well. Performance on divided attention and selective attention tasks was within normal limits (Test Battery for the Assessment of Attention or TAP). Stroop test performance was within normal limits as well.

\section{NUMBER CALCULATION AND ARITHMETIC}

Number processing and arithmetic were perfectly normal.

\section{INTELLIGENCE AND OVERALL COGNITIVE STATUS}

Several assessment procedures were used. In a test for estimating his verbal intelligence (MWT) ML was average. Also his performance in finding commonalities was average. On the other hand in non-verbal logical thinking ML was quite superior (IQ = 130). In other non-verbal tests of IQ his performance was superior to normal.

\section{SHORT-TERM AND WORKING MEMORY}

Performances on digit span forward and backward were above average in both numerical and visual tests. The surprising exception was an only average performance in visual block span forward (while the performance on visual block span backward was above average). Also ML was not prone to interference.

\section{VISUAL-CONSTRUCTIVE SKILLS}

In the Copy administration of the Rey-Osterrieth Figure ML reached points that situated his performance within normal limits. In the Mosaic test he was flawless.

\section{LONG-TERM MEMORY}

A large number of tests were applied to assess ML's long-term memory abilities. They can be divided into tests of anterograde, retrograde, and prospective memory, episodic-autobiographical, semantic, procedural, and priming memory (cf. Markowitsch and Staniloiu, 2012).

\section{Anterograde memory}

On all tests of anterograde memory, ML was below the level of normals (the only exception was that in the interference list of the VLMT he behaved substantially above average; this result can, however, be interpreted as reflecting his inability to properly acquire the main list of words, which was given prior to the interference list). Especially when it came to delayed recall of information he scored repeatedly at percentile 0 (VLMT, Logical Memory Subtest of the Wechsler Memory Scale-Revised, and Rey-Osterrieth 
Figure, delayed recall). Also in the Benton Visual Retention Test his performance was below average.

In more easy tasks of visual recognition he encountered much less problems (simple doors of the Doors and People Test) (Adlam et al., 2009). Also in recognition memory tests with emotional material he performed sub-average, but not as poorly as in free recall tests involving emotional material. During the Emotional Pictures Test, ML recognized only $60 \%$ of the emotional pictures, which places his performance far below that of the control group described in the study of von Cramon et al. (1993). Even more surprising was the high number (9) of falsely recognized distractors, i.e., of pictures he had not previously seen (cf. Table 1).

With respect to ML's performance in the picture story for affect induction (BAd), there were no differences in the free recall task of emotional versus non-emotional variant of the story. This suggests that his mnemonic performance did not benefit from the potential emotional enhancement (Markowitsch and Staniloiu, $2011 b)$. With respect to the recognition task of the emotional version of the story, ML recognized 18 out of 28 details (64\%) from the first pictures (1-4), 9 out of $21(42.8 \%)$ details from the pictures presented in the middle (5-7), and only 7 out of $21(33.3 \%)$ details from the pictures presented at the end (8-10). The pictures 5-7 are accompanied in the emotional variant of the story by an emotional narrative delivered by a male voice, while the other pictures are accompanied by a neutral narrative, which is identical for both the "emotional" and "neutral" versions of the story. In the study of Temizyürek (2003) that included 30 participants (mean age: $33.8+8.9$ years; $\mathrm{IQ}=108$ ), the percentage of recognized details from the "emotional" variant of the story was $83 \%$ for the first pictures (1-4), 77\% for the middle pictures (5-7), and $72.7 \%$ for the pictures presented at the end (8-10). The lower recognition of details from the last compared to the first part of the story in the case of ML may reflect forgetting in the context of cognitive overload (Corkin, 1984; Markowitsch et al., 1993).

\section{Retrograde semantic memory recognition}

In tests of retrograde semantic memory recognition ML, on the other hand, was principally normal (Semantic Old Memory Inventory, Famous Faces Test, Famous Names, Famous Terms, and Famous Events Tests).

\section{Retrograde autobiographical memory recall}

As it was evident from the Autobiographical Memory Inventory, $\mathrm{ML}$ was unable to recall any personal events apart from one outstanding event, where his father made a suicide attempt by jumping out of the window. On the other hand, he could list autobiographical semantic facts (date of birth, place of birth, schooling, and the like).

\section{Prospective memory}

His prospective memory appeared impaired (Rivermead Behavioral Memory Test; "The Grasshoppers and Geese Prospective Memory Test"). In the Rivermead Behavioral Memory Test ML did not spontaneously recall to ask back for the loaned item. He required several very explicit cues. After each cue he responded "Yes, there was something," without knowing what. When given alternatives, he finally selected the right response.
On the Grasshoppers and Geese Prospective Memory Test ML did not perform the required action after all three prompts. (When extending the prompts to six - which is against instructions - he finally recalled the action he needed to perform.)

\section{Procedural memory and priming}

His procedural and priming skills appeared to be intact.

\section{MALINGERING}

Tests of malingering partly yielded results which - for an individual with normal memory capacity - would be indicative of malingering. As ML was quite deficient in memory recall of new material in general, these test outcomes cannot be interpreted as providing evidence for feigning or malingering (Sollman and Berry, 2011).

\section{EXECUTIVE FUNCTIONS AND PROBLEM SOLVING ABILITIES}

ML's problem solving and executive abilities were to a large extent within normal limits. Cognitive estimation measures were impaired (TkS). In the TkS, ML showed similar deficits as patients with Korsakoff's syndrome (Brand et al., 2003a,b). He exhibited deficits in estimating dimensions "weight," "quantity," and "time," whereby time and weight estimations were the most deteriorated. Size estimation was normal. Deficits in the TkS time items had been speculated to depend on timing deficits combined with remote memory impairment (Brand et al., 2003a). [In the time estimation task used here the participant was asked to estimate the duration of specific events (e.g., duration of a morning shower) without experiencing them in the test situation itself (Brand et al., 2003a).]

In the Concept Comprehension Test (Cronin-Golomb et al., 1987a,b) ML's performance was sub-average for abstract, but within normal limits for concrete concepts (Martins et al., 2006). Performance on verbal FAS was below average as well, resembling other reports on patients with developmental amnesia (Temple and Richardson, 2006).

\section{SOCIAL INFORMATION PROCESSING: PERCEPTION OF EMOTIONAL AND COGNITIVE STATES AND INTERPERSONAL SITUATIONS}

In the German adaptation of the RMET ML was only slightly impaired. In terms of qualitative findings, he required a relatively long time to respond. He made eight mistakes, but had no difficulties with reading fear. He rated two female eye pairs as belonging to a male.

In the MASC his performance was again only slightly impaired. ML's performance in this task seemed much closer to that of the 20 healthy controls from the study of Dziobek et al. (2006) $(34.8+2.7)$ than to that of the 19 patients with Asperger's syndrome $(24.4+5.9)$ from the same study (cf. Table 1$)$.

In the Florida (Tübingen) Affect Battery ML displayed below average performance in the more complex subtests (affect naming, affect matching, affect prosody naming, detecting incongruent affect prosody, and matching face expression to affective prosody. In the visual affect naming subtest ML incorrectly designated the emotion of "fear" as being "anger" on two occasions. In the affect matching subtest, he made two mistakes, pertaining to the emotions "fear" and "happy," respectively. In the naming 
of affective prosody, he made two errors, pertaining to the emotion of happiness (which he interpreted as "neutral") and "fear." In the subtest requiring matching emotional faces to affective prosody he made one mistake, which involved the emotion of "fear." The most impaired was his performance on incongruent affective prosody, in which the semantic context was incongruent with prosody (Breitenstein et al., 1998; Snitz et al., 2002; Paulmann et al., 2008; Ward et al., 2012). While the degree of impairment detected in ML's performance should be interpreted with caution given the well-known ceiling effects of the Florida Battery Test, the qualitative description of these impairments is intriguing, when it is corroborated with findings from other tests, such as the Approachability Task or EWL-N (see below).

\section{OTHER TESTS OF SOCIAL INFORMATION PROCESSING}

The results in the Humor Appreciation Test (cartoons) were ambivalent. In the variation of Ultimatum Game ML accepted all the offers, including the minimal value (1 Euro) and in the Dictator Game he offered 15 Euros, which represents 15\% of the starting capital. Although this behavior is difficult to be accurately interpreted due to the non-standardized format of testing that we used, there are, in our opinion some hints of abnormal fairness attitudes (Scheele et al., 2012; Baumard et al., 2013). Incidentally abnormal fairness attitudes and socio-economical decisions have recently been related to amygdala dysfunction (Scheele et al., 2012).

Results of the Approachability Task are indicative of either heightened capacity for trust, or hypersociability (see Bellugi et al., 1999; Martens et al., 2009), or alternatively, decreased aversiveness (such as in patients with amygdala damage; Adolphs et al., 1998, 1999). In the task of Heider and Simmel, ML used a total of 83 words in his description, within the range of healthy participants (Curci-Marino et al., 2004). However, he did not use any animate noun and gave no description of internal states. This finding is interesting in the light of data from Curci-Marino et al. (2004). This study (which was conducted in a technical university and without any explicit indication that it was a psychological study) failed to replicate several findings of Heider and Simmel (1944). The latter had reported a high use of animate nouns in their sample (97.1\%). In the sample of Curci-Marino et al. (2004), 27 (59.3\% men) out of 40 participants $(67.5 \%, p<0.05)$ did not use any animate nouns; only 13 participants out of 40 did use animate nouns $(32.5 \%)$. The description of internal states was done by nine participants $(22.5 \%, p<0.01)$. Out of these participants six were men. Physical verbs were used by 39 participants and 38 participants described the moves of the figures with animated verbs among others. In contrast to Curci-Marino et al. (2004), the administration of the animation task of Heider and Simmel was done in our study as part of the psychological testing, which in theory could have offered ML a performance advantage.

\section{PSYCHIATRIC RATINGS, EMOTIONS, AND PERSONALITY}

The screening instrument Beck Depression Inventory did not yield scores suggestive of an affective disorder. ML did not show autistic tendencies (Autism-Spectrum-Quotient). In the Symptom Check List (SCL-90R) ML reported little tendency to somatize his problems, denied uncertainty in social situations or experiencing feelings of anxiety or inadequacy. In the FPI-R, ML answered that he had reduced life satisfaction, few physical complaints, very little aggressiveness, and perceived himself as being reserved and introverted. He experienced himself as being passive and with decreased motivation for achievement. On the openness subscale of FPI-R, ML scored significantly lower than his age group, seeming therefore to be very concerned with social conventions and social desirability. The subscale "openness" (willingness to admit minor weaknesses and violations of everyday conventions versus orientation toward making a socially desirable impression/social norms) of the FPI-R acts as a validity scale. Low results on this sub-scale point to socially desirable response tendencies. If a low result (stanines one to three) is reached in this subscale, interpretation of all other responses is limited (Fahrenberg et al., 2001; Fujiwara et al., 2008). According to findings from the self administration of Toronto Alexithymia Scale (TAS-26) ML did not experience any kind of difficulties with perceiving his own feelings and their accompanying bodily sensations. He scored low on the subscale for external orienting thinking style and perceived himself as being very interested in finding solutions in problematic situations. According to his self assessment, his ability to describe his own feelings was within normal limits. Given the deficient performance of ML on some tasks that objectively assessed emotional processing, one might argue that the results from self-evaluation scales or inventories should be interpreted cautiously. This is one of the reasons why we chose to ask both ML and his mother to complete the personal adjectives self-questionnaire (EWL-N). Both the mother and the patient confirmed that ML experienced no fear and no aggression. Out of 161 adjectives, 33 were judged differently by the two. ML's mother perceived ML as having no symptoms of depression and ML denied feeling depressed. While ML's mother perceived ML as being unconcentrated, undecided, and contemplative, ML viewed himself as being well concentrated, capable of decision making, and rejected all adjectives describing a contemplative or daydreaming nature. We speculate that ML's mother's perception of ML as being non-concentrated and a daydreamer might represent a misinterpretation of his memory difficulties (Gadian et al., 2000).

ML's capacity for empathy appeared even above average as assessed by one scale (Cambridge Behavior Scale). In the Saarbrücken Personality Questionnaire the only deviant scale score was that for personal distress. With a score of 85 on the latter scale ML supposedly experiences a lower (below average) level of personal distress (self oriented unpleasant feelings) when he is confronted with the distress of others. This scale's queries tap on aspects of emotional regulation. The low level of personal distress when confronted with the distress of others may also be corroborated with ML's view of himself as being interested in finding solutions in problematic situations. This pro-active attitude may be fueled by a decreased level of aversiveness or of conscious fear when confronted with various extreme situations, including the distress of others, which may be related to an amygdala dysfunction. Personal distress elicited by the distress of others is a self oriented motivated response directed toward self regulation of overarousal, which may be associated with fearfulness and emotional vulnerability (Cheetham et al., 2009). Too much personal distress might hinder the capacity for empathic concern; the amygdala and its connections seem to modulate the 
balance between the two (Feinstein et al., 2011; Roth-Hanania et al., 2011). The decreased level of aversiveness (probably due to an amygdalar dysfunction) may also account for the results on the approachability task, which were discussed above and for the behavior during administered variations of the economic games.

ML's scores on the fantasy scale, perspective-taking scale, and empathic concern scale fell within the average range (90-110), with the highest score (104) being achieved on the perspectivetaking scale. Findings of average scores on the fantasy scale support its relationship with measures of verbal intelligence (Shamay-Tsoory et al., 2009). The perspective-taking scale was repeatedly related to interpersonal functioning, increased self esteem and social competence (Shamay-Tsoory et al., 2009).

The conduction of a psychiatric interview in conformity with DSM-IV-TR (2000) did not provide evidence of meeting full diagnostic criteria for a concomitant major depressive disorder, dysthymic disorder, or bipolar disorder (or other psychiatric disorder, with the exception of adjustment disorder). No substance use disorder was diagnosed. ML did not meet diagnostic criteria for a pervasive developmental disorder. [However, in line with the results of a new small study showing that some individuals with autism spectrum disorder may lose their diagnosis, one could argue that ML might have outgrown a range of symptoms later on (Fein et al., 2013).]

\section{DISCUSSION}

According to our knowledge, this is one of the first reports about a comprehensive evaluation of social information processing in a patient with amnesia with neurodevelopmental mechanisms (probable developmental amnesia). ML has a long standing history of difficulties with acquiring EAMs for long-term storage and with everyday memory performance (Vargha-Khadem et al., 1997, 2003; Willoughby et al., 2012). These impairments occurred in the context of postnatal hypoxia and reduced hippocampal formation volumes bilaterally. The reduction in hippocampal volumes likely happened due to the hypoxic incident; as mentioned above, a bilateral enlargement of the lateral ventricles (which suggests hippocampal volume reductions; Calabrese and Penner, 2007) had been noted more than 10 years prior to ML's most recent MRI imaging. Our voxel-based morphometry data confirmed markedly reduced gray-matter density within the hippocampus bilaterally, with an anterior and right-sided preponderance. Only when we used a whole brain analysis with a less conservative statistical threshold ( $p<0.001$, uncorrected), we identified further regions showing reductions of gray matter, such as both amygdalae and bilateral striatum and pallidum, bilateral thalamus (pulvinar) again with a right-sided preponderance. Our findings partly overlap with the voxel-based morphometry results of Vargha-Khadem et al. (2003). One potentially intriguing result in our study is the reduction in the amygdala gray matter, when using a less conservative statistical threshold. The lack of reports of amygdala gray matter reductions in previous studies might be accounted for by the statistical threshold applied and/or the fact that apart from hippocampal formation, other medio-temporal lobe regions did not undergo rigorous volumetric quantifications (Vargha-Khadem et al., 2003; Rosenbaum et al., 2011). In line with other studies showing damage to thalamic areas after episodes of (perinatal) hypoxia (Jacob and Pyrkosch, 1951; Voit et al., 1987; Markowitsch et al., 1997; Cowan et al., 2003; Macey et al., 2005; de Haan et al., 2006), we identified indices of reductions in gray matter density in thalamus, namely in the pulvinar, when we applied a less conservative statistical threshold ( $p<0.001$, uncorrected).

The right-sided preponderance of the identified structural brain changes is relevant, given data suggesting a right hemispheric bias for emotional processing (Schore, 2002), EAM (Fink et al., 1996; Markowitsch et al., 2000) and "high-order consciousness” (Keenan et al., 2005) (however, for different results, see Nyberg et al., 2010; Viard et al., 2012).

On the behavioral level, ML shared several similarities with patients with developmental amnesia, but also displayed some distinct features (such as atypical school trajectory, different level of functional independence). He showed evidence of at least average intelligence; in some measures of intelligence his performance even was substantially above the normal level. His attention and concentration abilities were at least average and for some tests, above average. The same held true for executive functions and problem solving abilities, which were to a large degree within normal range. In the Concept Comprehension Test (Cronin-Golomb et al., 1987a,b) ML showed intact performance for concrete concepts, but sub-average for abstract concepts (Martins et al., 2006; Quian Quiroga, 2012). This result is congruent with data suggesting a role of hippocampal formation in facilitation of more complex problem solving, via comparison computations (Olsen et al., 2012). In the TkS, ML showed impairments comparable to those of patients with Korsakoff's syndrome (Brand et al., 2003a). These results may have to do with the test's specification. As mentioned above, deficits in the TkS time items had been conjectured to depend on timing deficits combined with remote memory impairment (Brand et al., 2003a).

ML's major and in fact very severe problems were identified in the domains of long-term memory. This was evident in anterograde memory tests where he almost did not recall anything after half an hour delay. It was - if this comparison is possible - even more evident when it came to EAM recall. ML was completely unable to provide authentic memories for personal events, aside from one, where his father jumped out of the window in a suicide attempt. The recall of this extraordinary event can be compared with the islands of knowledge that had been found in patient H.M. of Scoville and Milner (1957) and Corkin (2002). (After surgical removal of his medial temporal lobe regions bilaterally, H.M. was completely anterogradely amnesic. Exceptions were that he could recall the death of his parents, the killing of President Kennedy, and a particular song. All these were, however, semanticized memories; cf. Markowitsch, 1985.)

ML showed impairments in both semantic and episodicautobiographical anterograde memory. He for example had no recollection of a previous meeting with one of his examiners (AS), although he admitted to a feeling of familiarity. He was able to recall factual aspects of his meetings with examiner SB, but these memories did not have an episodic quality. In particular they lacked contextual details and the subjective feeling of reliving. In contrast to his performance on various anterograde explicit memory tests, his old semantic knowledge was good, which suggests a use of compensatory strategies (Rosenbaum et al., 2011). His 
performance on free recall was worse than that on recognition which is consistent with findings from patients with developmental amnesia (Adlam et al., 2009). Adlam et al. (2009) reported a dissociation between recall and recognition; this was however incomplete, in the sense that their patients with developmental amnesia displayed (similarly to ML) a subtle, but significant visual recognition impairment in the Doors test. ML's poor performance on prospective memory tests mirrors data suggesting a role for hippocampal formation in prospection (however, see Markowitsch and Staniloiu, 2012 for controversial results). Prospective memory impairments have been linked not only to deficits in executive functions, but also to deficits in semantic memory and episodicautobiographical memory (Hainselin et al., 2011). Apart from the hippocampal formation, the amygdala was also suggested to be involved in the simulation of future emotional events. In particular, a strong connectivity between rostral anterior cingulate cortex (ACC) and amygdala was observed during the imagination of positive future events (Sharot et al., 2007) and was postulated to underlie traits like optimism bias.

ML's performance on tasks that tap on social information processing abilities revealed both domains of preserved performance and impairment. In the Florida (Tübingen) Affect Battery ML performed well on simple tasks, but he displayed below average performance in the more complex subtests. Difficulties with emotional processing were also apparent on tests that assessed recognition and free recall of emotional stimuli. In the picture story for affect induction (BAd), his performance showed only a marginal benefit from the enhancing effect of emotional connotation. From a neurobiological perspective, ML's difficulties with emotional processing may be related to his gray matter reductions in hippocampal formation (with an anterior preponderance; Fanselow and Dong, 2010; Viard et al., 2012), and/or possible amygdala, basal ganglia (caudate), and pulvinar dysfunctions (Adolphs, 2010b; Markowitsch and Staniloiu, 2011b; Geschwind et al., 2012; Kemp et al., 2012; Nguyen et al., 2013; Saalmann and Kastner, 2013). Performance on affect-related memory tasks had been found to be impaired in patients with bilateral amygdala calcifications due to a genetic disorder (Urbach-Wiethe disease), compared to normal participants (Sarter and Markowitsch, 1985a,b; Cahill et al., 1995; Siebert et al., 2003). Similarly to the amygdala (Markowitsch and Staniloiu, 2011b), the pulvinar has been postulated to play a role in detecting salience (van Buren and Borke, 1972; Pessoa, 2011) and, due to its extensive connections with cortical areas, in the processing of emotional material (Pessoa, 2008, 2011; Pessoa and Adolphs, 2010). The hippocampal formation has been attributed a role not only in cognition, but also in emotional processing. In particular, the anterior hippocampus (which was significantly affected in our patient) has been assigned a function in emotional processing, reward, goal proximity, and arousal (Fanselow and Dong, 2010; Viard et al., 2012); the nature of functional specialization within the hippocampal formation in particular (and medio-temporal lobe, in general) is yet not a solved issue, however (Chua et al., 2007; Markowitsch and Staniloiu, 2012). Furthermore, it has been proposed that the function of the hippocampus extends beyond the mnemonic domain, to support other cognitive areas (such as perception, problem solving) via relational binding and comparison (Abu-Akel and Shamay-Tsoory, 2011; Olsen et al., 2012).
Some authors hypothesized that the hippocampal formation may play a role in the experience of emotions about others' mental states (Immordino-Yang and Singh, 2013). Negative correlations were found in a study between vocally expressed nervousness and regional cerebral blood flow in the right hippocampus (Laukka et al., 2011). Right temporal cortices (including right anterior temporal structures), the right thalamus, and also the amygdala and orbitofrontal cortices have been involved in affective-prosodic comprehension by some studies (Ross and Monnot, 2011). Additionally, basal ganglia have at times been implicated in emotional prosody decoding (Paulmann et al., 2008; Frühholz et al., 2012). While some authors had linked affective prosody decoding with the right hemisphere, several others have challenged this view (for a review, see Snitz et al., 2002; Frühholz et al., 2012). It is perhaps worth mentioning that the performance of ML on affective prosody tasks resembled in several respects that of the seven patients with Korsakoff syndrome, who were examined by Snitz et al. (2002). Those patients showed in comparison to control participants impairments in naming affective prosody when semantic content was incongruent, while both linguistic and affective prosody discriminations were intact. The authors did not provide a neurobiological explanation for their findings, though they made speculations about the involvement of the basolateral circuit.

On several standard laboratory tests for ToM, ML showed normal performance or only mild impairment. These results are consistent with largely preserved core ToM functions: however, our findings are slightly different from those of Rabin et al. (2012) who reported normal performance on standardized tests for ToM in an adult woman with developmental amnesia. There are several factors that may account for the observed differences, such as the use of different test adaptations (e.g., the German adaptation of the RMET) and the presence of neural correlates' and sex differences (Schulte-Rüther et al., 2008; Frank, 2012; Kemp et al., 2012; Nguyen et al., 2013; Saalmann and Kastner, 2013). In particular, the imaging study of Frank (2012) found that young men recruit during a false belief task more brain regions known to be implicated in episodic memory than young women.

In the Heider and Simmel animation paradigm ML partly deviated in his responses from those of comparison groups. Contrary to controls he did not use animated nouns and gave no description of internal states (Ross and Olson, 2010). On the other hand, self questionnaires yielded no indications of difficulties with empathy or perspective-taking apart from the Saarbrücken Personality Questionnaire (personal distress scale). As commented above, low personal distress elicited by the distress of others may reflect decreased conscious fearfulness (Cheetham et al., 2009), perhaps in the context of an anterior hippocampus and/or amyg-dalar dysfunction (Maren and Holt, 2004; Fanselow and Dong, 2010; Feinstein et al., 2011). Incidentally, on the EWLN [List of personal adjectives] (Janke and Debus, 1978), both ML's mother and ML consistently rejected adjectives synonyms to "fearful" as applying to ML.

ML's results on the approachability task could be interpreted as evidence of increased sociability and/or decreased aversiveness. He tended to overrate (both negative and positive) faces as being approachable. These findings corresponded to observations from 
ML's everyday life behavior. From a neurobiological perspective, an interaction between insula (which has bidirectional connections to amygdala) and hippocampus was found to be important for processing of untrustworthy faces (Tsukiura et al., 2012). Furthermore, decreased aversiveness and/or hypersociability have been related to various amygdala dysfunctions (Bellugi et al., 1999; Martens et al., 2009). It is possible that the hypersociability may stem in ML's case from decreased fearfulness/aversion, which may be underlain by an anterior hippocampus and/or amygdalar dysfunction (Maren and Holt, 2004; Fanselow and Dong, 2010; Feinstein et al., 2011).

No tendency for risky behavior was identified in ML by his performance in the Game of Dice Task. This finding is in some contradiction with his increased trustworthiness leading him to engage in potentionally risky or dangerous behaviors.

Tests of malingering partly yielded results which - for an individual with normal conscious mnemonic processing abilities would be indicative of feigning. As ML was quite deficient in memory recall of new material in general, these test outcomes cannot be interpreted as indicative of feigning. Based on our objective multidimensional assessment and the collateral information we obtained, we concluded that it was extremely unlikely that ML was trying to feign his impairments (either for an external incentive, such as in malingering or for deliberately trying to assume the sick role).

\section{CONCLUSION}

Episodic-autobiographical memory contains a wealth of information about people and social interactions; this led several authors to hypothesize that the exchange of EAM might facilitate social cognition, such as understanding of others' inner world and perspective (Nelson and Fivush, 2004; Spreng et al., 2008) and subsequently might connect and "draw the world together" (Casey, 2000, p. 313). In a review article, Abu-Akel and Shamay-Tsoory (2011) argued that, while primarily perception-based, the representation of mental states of others might also be computed by resorting to internally stored information such as from episodicautobiographical memories. Data coming from a study of healthy participants suggested that laboratory ToM tasks engage more cognitively economical ways than accessing own EAMs (Rabin et al., 2010), relying on semantic knowledge and/or implicit processing (Adolphs, 2010a; Staniloiu et al., 2010b). Yet another study, which investigated the role of hippocampus in emotional mentalizing, proposed that mentalizing is modulated by memories of past events (Perry et al., 2011). Interesting data came from a recent study of Rabin and Rosenbaum (2012), which showed that in healthy female participants the functional relation between autobiographical memory and ToM is modulated by the familiarity of the target person in a ToM task, which in turn affected the employment of cognitive strategies.

Herein we used a broad variety of tests and found objective evidence of intact areas as well as impaired domains of social information processing in a young adult male patient with amnesia with neurodevelopmental mechanisms, which preponderantly afflicted episodic-autobiographical mnemonic processing. Consistent with data from other authors (Rabin et al., 2012), we identified in ML's case largely preserved ability to perform on a number of tasks testing core ToM functions; this is in line with suggestions that neither intact EAM nor an intact hippocampal formation are essential for core social cognitive processes (Rosenbaum et al., 2007; Rabin et al., 2012). Impairments were however detected in ML's case on certain tasks taping on complex social perception or complex social judgments. These results could be interpreted in different ways. The hippocampal formation has been attributed roles in relational binding (flexible association of disparate items) and comparison computations (Olsen et al., 2012). The hippocampusrelated relational binding was proposed to underlie constructive processes linked to EAM, mental scene construction, and selfprojection (Spreng et al., 2008; Addis et al., 2009; Rosenbaum et al., 2009; Spreng and Grady, 2010) (but, see McKinlay et al., 2009; Squire et al., 2010 for different opinions). Furthermore, hippocampus-mediated constructive processes were suggested in a recent study to be implicated in both EAM and ToM tasks targeting familiar individuals (Rabin and Rosenbaum, 2012). An interesting idea was however put forth by Olsen et al. (2012). The authors stated: "Thus, while binding and comparison computations may be mediated by multiple neural regions, the hippocampus is critical for these computations when relational information must be maintained over longer delays and/or when information has a high degree of conceptual/perceptual overlap, regardless of whether the information must be maintained over a delay or merely discriminated in the present moment" (Olsen et al., 2012, p. 10). Along this vein we could argue that our findings support ideas that an intact hippocampal formation might be necessary for adequate performance on tasks that require demanding, complex (perceptual) information processing, involving complex relational information and/or a need for longer online holding of complex relational information (Olsen et al., 2012).

Alternative explanations for our results may be linked to our voxel-based morphometry data, which pointed to indices of reduced gray matter in amygdala, basal ganglia, and pulvinar, when a less conservative threshold was used. All these structures were described to make contribution to social cognition and social information processing (Jacobson, 1986; Adolphs et al., 1998, 1999, 2005; Shaw et al., 2004; Pessoa, 2008, 2011; Adolphs, 2010a,b; Bodden et al., 2010a,b; Pessoa and Adolphs, 2010; Kemp et al., 2012; Nguyen et al., 2013; Saalmann and Kastner, 2013). Furthermore, several of these structures were reported to be affected in various memory disorders (Zingerle, 1912; Schuster, 1936; Smyth and Stern, 1938; Stern, 1939; Guard et al., 1986; Kuljis, 1994; Mori et al., 1999; Siebert et al., 2003; Allen et al., 2006). While white matter changes were not detected on visual inspection in the case of ML, subtle white matter changes due to hypoxia cannot be ruled out and would require more refined imaging techniques in order to be captured (Paus, 2010). Their detection may however be relevant for a number of reasons: there are numerous reports on amnesia arising after white matter lesions (Horel, 1978; Zola-Morgan et al., 1982; Markowitsch et al., 1990; Calabrese et al., 1995; Markowitsch and Staniloiu, 2012); furthermore, there are some reports of ToM impairments occurring after white matter tract damage (Bach et al., 1998; Happé et al., 2001).

Due to their non-uniformity, our findings draw attention to the need of employing several tests for assessing social information processing. Furthermore, they call for testing social cognition 
in real life settings or conditions that approximate real life settings, in order to fully assess the extent of disability and appreciate any contribution that EAM may play to understanding the inner world of others and "drawing the world together" (Casey, 2000, p. 313).

\section{REFERENCES}

Abu-Akel, A., and Shamay-Tsoory,

S. (2011). Neuroanatomical and neurochemical bases of theory of mind. Neuropsychologia 49, 2971-2984. doi:10.1016/j.neuro psychologia.2011.07.012

Addis, D. R., Pan, L., Vu, M. A., Laiser, N., and Schacter, D. L. (2009). Constructive episodic simulation of the future and the past: distinct subsystems of a core brain network mediate imagining and remembering. Neuropsy-chologia 47, 2222-2238. doi:10.1016/j.neuro psychologia.2008.10.026

Adenauer, H., Kessler, J., Brand, M., Fleck, S., Lechmann, C., Prim, W., et al. (2005). Vergleich verschiedener deutschsprachiger Theory-of-Mind Tests bei Menschen mit Asperger Syndrom. Presentation at the 78th Congress of the German Society for Neurology.

Adlam, A. L. R., Malloy, M., Mishkin, M., and Vargha-Khadem, F. (2009). Dissociation between recognition and recall in developmental amnesia. Neuropsychologia 47, 2207-2210. doi:10.1016/j.neuro psychologia.2009.01.038

Adolphs, R. (2010a). Conceptual challenges and directions for social neuroscience. Neuron 65, 752-767. doi:10.1016/j.neuron.2010.03.006

Adolphs, R. (2010b). What does the amygdala contribute to social cognition? Ann. N. Y. Acad. Sci. 1191, 42-61. doi:10.1111/j.17496632.2010.05445.x

Adolphs, R., Tranel, D., and Buchanan, T. W. (2005). Amygdala damage impairs emotional memory for gist but not details of complex stimuli. Nat. Neurosci. 8, 512-518.

Adolphs, R., Tranel, D., and Damasio, A. R. (1998). The human amygdala in social judgment. Nature 393, 470-474. doi:10.1038/30982

Adolphs, R., Tranel, D., Hamann, S., Young, A. W., Calder, A. J., Phelps, E. A., et al. (1999). Recognition of facial emotion in nine individuals with bilateral amygdala damage. Neu-ropsychologia 37, 1111-1117. doi:10.1016/S00283932(99)00023-8

Allen, J. S., Tranel, D., Bruss, J., and Damasio, H. (2006). Correlations between regional brain volumes and memory performance in anoxia. J. Clin.
Exp. Neuropsychol. 28, 457-476. doi:10.1080/13803390590949287

Aster, M., von Neubauer, A., and Horn, R. (2006). Wechsler Intelligenztest für Erwachsene WIE. Übersetzung und Adaptation der WAIS-III von David Wechsler. Frankfurt: Harcourt Test Sources.

Bach, I., Davis, S., Colvin, C., Wijerante, C., Happé, F., and Howard, R. (1998). A neuropsychologi-cal investigation of theory of mind in an elderly lady with frontal leucotomy. Cogn. Neuropsy-chiatry 3, 139-159. doi:10.1080/ 135468098396215

Baddeley, A., Emslie, H., and NimmoSmith, I. (1994). Doors and People Test. Bury St. Edmunds: Thames Valley Test Company.

Baron-Cohen, S., Hoekstra, R. A., Knickmeyer, R., and Wheelwright, S. (2006). The autism-spectrum quotient (AQ)- adolescent version. J. Autism Dev. Disord. 36, 343-350. doi:10.1007/s10803-006-0073-6

Baron-Cohen, S., Wheelwright, S. Hill, J., Raste, Y., and Plumb, I. (2001). The "Reading the Mind in the Eyes" test revised version: a study with normal adults, and adults with Asperger syndrome or high-functioning autism. J. Child Psychol. Psychiatry 42, 241-251. doi:10.1111/1469-7610.00715

Batson, C. D., Sympson, S. C., Hindman, J. L., Decruz, P., Todd, R. M., Weeks, J. L., et al. (1996). "I've been there, too": effect on empathy of prior experience with a need. Pers. Soc. Psychol. Bull. 22, 474-482. doi:10.1177/ 0146167296225005

Baumard, N., Andre, J. B., and Sperber, D. (2013). A mutualistic approach to morality: the evolution of fairness by partner choice. Brain Behav. Sci. 36, 59-78. doi:10.1017/S0140525 X11002202

Bäumler, G. (1985). Farbe-WortInterferenztest (FWIT) nach J. R. Stroop. Göttingen: Hogrefe.

Bellugi, U., Adolphs, R., Cassady, C., and Schiles, M. (1999). Towards the neural basis for hypersociability in a genetic syndrome. Neuroreport 10 , 1653-1657. doi:10.1097/00001756199906030-00006

Beven, J. P., O’Brien-Malone, A., and Hall, G. (2004). Using the interpersonal reactivity index to assess

\section{ACKNOWLEDGMENTS}

Research was supported by CITEC and the University of Bielefeld. We thank ML for his patience and cooperation. Ralph Adolphs we thank for sharing with us the stimuli of his Approachability Task.

empathy in violent offenders. Int. J. Forensic Psychol. 1, 33-41.

Bindschaedler, C., Peter-Favre, C., Maeder, P., Hirsbrunner, T., and Clarke, S. (2011). Growing up with bilateral hippocampal atrophy: from childhood to teenage. Cortex 47, 931-944. doi:10.1016/j.cortex.2010.09.005

Bird, C. M., Castelli, F., Malik, O., Frith, U., and Husain, M. (2004). The impact of extensive medial frontal lobe damage on "theory of mind" and cognition. Brain 127, 914-928. doi:10.1093/brain/awh108

Bluck, S., Alea, N., Habermas, T. and Rubin, D. (2005). A tale of three functions: the self-reported uses of autobiographical memory. Soc. Cogn. 23, 91-117. doi:10.1521/soco.23.1.91.59198

Bodden, M. E., Dodel, R., and Kalbe, E. (2010a). Theory of mind in Parkinson's disease and related basal ganglia disorders: a systematic review. Mov. Dis. 25, 13-27. doi:10.1002/mds. 22818

Bodden, M. E., Mollenhauer, B. Trenkwalder, C., Cabanel, N., Eggert, K. M., Unger, M. M. et al. (2010b). Affective and cognitive theory of mind in patients with Parkinson's disease. Parkinsonism Relat. Dis. 16, 466-470. doi:10.1016/j.parkreldis.2010.04.014

Bolton, G. E., and Ockenfels, A. (1998) Strategyandequity:anERC-analysis of the Güth-van Damme game. J. Math. Psychol. 42, 215-226. doi:10.1006/jmps.1998.1211

Borsutzky, S., Fujiwara, E., Brand, M. and Markowitsch, H. J. (2008) Confabulations in alcoholic Korsakoff patients. Neuropsychologia 46 3133-3143. doi:10.1016/j.neuro psychologia.2008.07.005

Borsutzky, S., Fujiwara, E., Brand, M., and Markowitsch, H. J. (2010). Susceptibility to false memories in patients with ACoA aneurysm. Neuropsychologia 48 2811-2823. doi:10.1016/j.neuro psychologia.2010.05.023

Borys, S. V., Spitz, H. H., and Doans, B. A. (1982). Tower of Hanoi performance of retarded young adults and nonretarded children as a function of solution length and goal state. J. Exp. Child Psychol. 33, 87-110. doi:10.1016/0022-0965(82)90008-X

Bowers, D., Blonder, L. X., and Heilman, K. M. (1991). The Florida
Affect Bat-tery. Miami, FL: Florida University Press.

Brand, M., Fujiwara, E., Borsutzky, S., Kalbe, E., Kessler, J., and Markowitsch, H. J. (2005). Decision-making deficits of Korsakoff patients in a new gambling task with explicit rules: associations with executive functions. Neuropsychol-ogy 19, 267-277. doi:10.1037/0894-4105. 19.3.267

Brand, M., Fujiwara, E., Kalbe, E., Steingass, H. P., Kessler, J., and Markowitsch, H. J. (2003a). Cognitive estimation and affective judgments in alcoholic Korsakoff patients. J. Clin. Exp. Neuropsychol. 25, 324-334. doi:10.1076/jcen.25.3.324.13802

Brand, M., Kalbe, E., Fujiwara, E., Huber, M., and Markowitsch, H. J. (2003b). Cognitive estimation in patients with probable Alzheimer's disease and alcoholic Korsakoff patients. Neuropsychologia 41, 575-584. doi:10.1016/S0028 3932(02)00183-5

Brand, M., Kalbe, E., and Kessler, J. (2002). Test zum kognitiven Schätzen (TkS). Göttingen: Hogrefe.

Brand, M., and Markowitsch, H. J. (2010). Mechanisms contributing to decision-making difficulties in late adulthood: theoretical approaches, speculations and empirical evidence. Gerontology 56, 435-440. doi:10.1159/000300569

Breitenstein, C., Daum, I., and Ackermann, H. (1998). Emotional processing following cortical and subcortical brain damage: contribution of the fronto-striatal circuitry. Behav. Neurol. 11 29-42.

Breitenstein, C., Daum, I., Ackermann, H., Lütgehetmann, R., and Müller, E. (1996). Erfassung der Emotionswahrnehmung bei zentral-nervösen Läsionen und Erkrankun-gen: psychometrische Gütekriterien der "Tübinger Affekt Batterie.” J. Neurol. Rehabil. 2, 93-101.

Cahill, L., Babinsky, R., Markowitsch, H. J., and McGaugh, J. L. (1995). Involvement of the amygdaloid complex in emotional memory. Nature 377, 295-296. doi:10.1038/377295a0

Calabrese, P., and Kessler, J. (2000). Dem Tect. Frankfurt: EISAI. 
Calabrese, P., Markowitsch, H. J., Harders, A. G., Scholz, A., and Gehlen, W. (1995). Fornix damage and memory: a case report. Cortex 31, 555-564. doi:10.1016/S00109452(13)80066-4

Calabrese, P., and Penner, I. K. (2007). Cognitive dysfunctions in multiple sclerosis - a "multiple disconnection syndrome?" J. Neurol. 254(Suppl. 2), 1118-1121. doi:10.1007/s00415-007-2006-5

Casey, E. S. (2000). Remembering: A phenomenological Study, 2nd Edn. Bloomington, IN: Indiana University Press.

Castelli, F., Happe, F., Frith, U., and Frith, C. (2000). Movement and mind: a functional imaging study of perception and interpretation of complex intentional movement patterns. Neuroimage 12, 314-325. doi:10.1006/nimg.2000.0612

Cheetham, M., Pedroni, A. F., Antley, A., Slater, M., and Jancke, L. (2009). Virtual milgram: empathic concern or personal distress? Evidence from functional MRI and dispositional measures. Front. Hum. Neurosci. 3:29. doi:10.3389/neuro.09.029.2009

Chua, E. F., Schacter, D. L., RandGiovannetti, E., and Sperling, R. A. (2007). Evidence for a specific role of the anterior hippocampal region in successful associative encoding. Hippocampus 17, 1071-1080. doi:10.1002/hipo.20340

Connolly, D. J., Widjaja, E., and Griffiths, P. D. (2007). Involvement of the anterior lobe of the cerebellar vermis in perinatal profound hypoxia. AJNR Am. J. Neuroradiol. 28, 16-19.

Corcoran, R., and Frith, C. D. (2003). Autobiographical memory and theory of mind: evidence of a relationship in schizophrenia. Psychol. Med. 33, 897-905. doi:10.1017/S0033291703007529

Corkin, S. (1984). Lasting consequences of bilateral medial temporal lobec-tomy: clinical course and experimental findings in H.M. Semin. Neu-rol. 4, 249-259. doi:10.1055/s-2008-1041556

Corkin, S. (2002). What's new with the amnesic patient H.M.? Neuroscience 3, 153-160.

Cowan, F., Rutherford, M., Groenendaal, F., Eken, P., Mercuri, E., Bydder, G. M., et al. (2003). Origin and timing of brain lesions in term infants with neonatal encephalopathy. Lancet 361, 736-742. doi:10.1016/S01406736(03)12658-X

Craig, M. C., Catani, M., Deeley, Q., Latham, R., Daly, E., Kanaan, R., et al. (2009). Altered connections on the road to psychopathy. Mol. Psychiatry 14, 907. doi:10.1038/mp.2009.40

Croft, K. E., Duff, M. C., Kovach, C. K., Anderson, S. W., Adolphs, R., and Tranel, D. (2010). Detestable or marvellous? Neuroanatomical correlates of character judgment. Neuropsychologia 48, 1789-1801. doi:10.1016/j

Cronin-Golomb, A., Rho, W. A., Corkin, S., and Growdon, J. H. (1987a). Abstract reasoning in age-related neurological disease. J. Neural Transm. Suppl. 24, 79-83.

Cronin-Golomb, A., Rho, W. A., Corkin, S., and Growdon, J. H. (1987b). Rela-tional abilities in Alzheimer's disease and Parkinson's disease. Clin. Neuropsychol. 1, 298.

Curci-Marino, L., Spörrle, M., Hinterseer, P., and Försterling, F. (2004). "Zur Personenwahrnehmung im Attributionsgeschehen: Eine Replikation der klassischen Arbeit von Heider und Simmel (1944)," in Beiträge zur 46. Tagung experimentell arbeitender Psychologen, eds D. Kerzel, V. Franz, and K. Gegen-furtner (Lengerich: Pabst Science Publishers), 56.

Cusi, A. M., Macqueen, G. M., Spreng, R. N., and McKinnon, M. C. (2011). Altered empathic responding in major depressive disorder: relation to symptom severity, illness burden, and psychosocial outcome. Psychiatry Res. 188, 231-236. doi:10.1016/j.psychres.2011.04.013

Dahl, G. (1972). WIP-Reduzierter Wechsler-Intelligenztest. Meisenheim: Hain.

de Haan, M., Wyatt, J. S., Roth, S., Vargha-Khadem, F., Gadian, D., and Mishkin, M. (2006). Brain and cognitive-behavioural development after asphyxia at term birth. Dev. Sci. 9, 350-358. doi:10.1111/j.14677687.2006.00499.x

de Haen, J. (2006). Deutsche Version der Cambridge Behaviour Scale. Bochum: AUTISMO Praxis Autismus Therapie.

Delis, D. C., Kramer, J., Kaplan, E., and Ober, B. A. (1987). California Verbal Learning Test (CVLT). San Antonio, TX: Psychological Corporation.

Delis, D. C., Squire, L. R., Bihrle, A., and Massman, P. (1992). Componential analysis of problem-solving ability: performance of patients with frontal lobe damage and amnesic patients on a new card sorting test. Neuropsychologia 30, 683-697. doi:10.1016/00283932(92)90039-O

Dennis, M., Purvis, K., Barnes, M. A., Wilkinson, M., and Winner,
E. (2001). Understanding of literal truth, ironic criticism, and deceptive praise following childhood head injury. Brain Lang. 78, 1-16. doi:10.1006/brln.2000.2431

DSM-IV-TR. (2000). Diagnostic and Statistical Manual of Mental Disorders, 4th Edn. Washington, DC: American Psychiatric Association.

Dziobek, I., Fleck, S., Kalbe, E., Rogers, K., Hassenstab, J., Brand, M., et al. (2006). Introducing MASC: a movie for the assessment of social cognition. J. Autism Dev. Dis. 36, 623-636. doi:10.1007/s10803-0060107-0

Ehrenstein, W. H., and Arnold-SchulzGahmen, B. E. (1997). Auge, Ohr, Handund Fu $\beta$ : Bestimmung des individuellen Lateralitätsprofils. Fragebo-gen. Dortmund: IfADo.

Fahrenberg, J., Hampel, R., and Selg, H. (2001). Das Freiburger Persönlichkeitsinventar (FPI-R), 7th Edn. Göttingen: Hogrefe.

Fanselow, M. S., and Dong, H. W. (2010). Are the dorsal and ventral hippocampus functionally distinct structures? Neuron 65, 7-19. doi:10.1016/j.neuron.2009.11.031

Fast, K., Fujiwara, E., Schröder, J., and Markowitsch, H. J. (2013). Erweitertes Autobiographisches Gedachtnis Interview (E-AGI). Frankfurt: Harcourt.

Fein, D., Barton, M., Eigsti, I. M. Kelley, E., Naigles, L., Schultz, R. T., et al. (2013). Optimal outcome in individuals with a history of autism. J. Child Psychol. Psychiatry 54, 195 205. doi:10.1111/jcpp.12037

Feinstein, J. S., Adolphs, R., Damasio, A., and Tranel, D. (2011). The human amygdala and the induction and experience of fear. Curr. Biol. 21, 34-38. doi:10.1016/j.cub.2010.11.042

Fimm, B., and Zimmermann, P. (2001). Testbatterie zur Aufmerksamkeitsprü-fung (TAP), Version 1.6. Herzogen-rath: Psytest.

Fink, G. R., Markowitsch, H. J. Reinkemeier, M., Bruckbauer, T., Kessler, J., and Heiss, W.-D. (1996). Cerebral representation of one's own past: neural networks involved in autobiographical memory. J. Neurosci. 16, 4275-4282.

Fleck, S. (2008). Theory of Mind bei Schizophrenie und AspergerSyndrom. Saarbrücken: VDM Verlag Dr. Müller.

Fleck, S., Kalbe, E., Dziobek, I., Brand, M., Ruhrmann, S., and Kessler, J. (2002). Qualitative differences of "theory of mind" (ToM) impairments in schizophrenia. Eur. J. Neurol. 9(Suppl. 2), 211.
Frank, C. K. (2012). Sex difference in neural correlates of theory of mind. Eur. Psychiatry 27(Suppl. 1), 1. doi:10.1016/S0924-9338(12) 74528-5

Frühholz, S., Ceravolo, L., and Grandjean, D. (2012). Specific brain networks during explicit and implicit decoding of emotional prosody. Cereb. Cortex 22, 1107-1117. doi:10.1093/cercor/ bhr184

Fujiwara, E. (2004). Brain and Behaviour in Functional Retrograde Amnesia. Dissertation, University of Bielefeld, Bielefeld. Available at: http://pub.uni-bielefeld.de/ publication/2304388

Fujiwara, E., Brand, M., Kracht, L., Kessler, J., Diebel, A., Netz, J., et al. (2008). Functional retrograde amnesia: a multiple case study. Cortex 44, 29-45. doi:10.1016/j. cortex.2005.09.001

Gadian, D. G., Aicardi, J., Watkins, K. E., Porter, D. A., Mishkin, M., and Vargha-Khadem, F. (2000). Developmental amnesia associated with early hypoxic-ischaemic injury. Brain 123(Pt 3), 499-507. doi:10. 1093/brain/123.3.499

Geschwind, M., Pourtois, G., Schwartz, S., van de Ville, D., and Vuilleumier, P. (2012). White-matter connectivity between face-responsive regions in the human brain. Cereb. Cortex 22, 1564-1576. doi:10.1093/cercor/ bhr226

Golden, C. J., Espe-Pfeifer, P., and Wachsler-Felder, J. (2002). Neuropsychological Interpretation of Objective Psychological Tests. New York: Kluver.

Gollin, E. S. (1960). Developmental studies of visual recognition of incomplete objects. Percept. Mot. Skills 11, 289-298. doi:10.2466/pms. 1960.11.3.289

Guard, O., Bellis, F., Mabille, J. P., Dumas, R., Boisson, D., and Devic, M. (1986). Démence thalamique après lésion hém-orrhagique unilatérale du pulvinar droit. Rev. Neurol. 142, 759-765.

Hainselin, M., Quinette, P., Desgranges, B., Martinaud, O., Hannequin, D. de La Sayette, V., et al. (2011). Can we remember future actions yet forget the last two minutes? Study in transient global amnesia. J. Cogn. Neurosci. 23, 4138-4149. doi:10.1162/jocn_a_00076

Happé, F., Brownell, H., and Winner, E. (1999). Acquired 'theory of mind' impairments following stroke. Cognition 70, 211-240. doi:10.1016/ S0010-0277(99)00005-0

Happé, F., Malhi, G. S., and Checkley, S. (2001). Acquired mind-blindness 
following frontal lobe surgery? A single case study of impaired "theoryofmind"inapatienttreated with stereotactic anterior capsulo-tomy. Neuropsychologia 39, 83-90. doi:10. 1016/S0028-3932(00)00093-2

Härting, C., Markowitsch, H. J., Neufeld, H., Calabrese, P., Deisinger, K., and Kessler, J. (2000). Die Wechsler-Memory-Scale Revised. Deutschsprachige Adaptation. Bern: Huber.

Hautzinger, M., Keller, F., and Kühner, C. (2006). Beck-Depressionsinventar II (BDI-II). Frankfurt: Harcourt Test Services.

Heider, F., and Simmel, M. (1944). An experimental study of apparent behavior. Am. J. Psychol. 57, 243-249. doi:10.2307/1416950

Helmstaedter, C., Lendt, M., and Lux, S. (2001). Verbaler Lern- und Merkfähigkeitstest (VLMT). Göttingen: Hogrefe.

Hessel, A., Schumacher, J., Geyer, M., and Brähler, E. (2001). Symptomcheckliste SCL-90-R: testtheoretische Überprüfung und Normierung an einer bevölkerungsreprasentativen Stichprobe. Diagnostica 47, 27-39. doi:10.1026//0012-1924.47. 1.27

Heubrock, D., and Petermann, F. (2000). Testbatterie zur Forensischen Neuropsychologie (TBFN). Frankfurt: Swets and Zeitlinger.

Hoppe, C., Müller, U., Werheid, K., Thöne, A., and von Cramon, D. Y. (2000). Digit ordering test: clinical, psychometric, and experimental evaluation of a verbal working memory test. Clin. Neuropsychol. 14, 38-55. doi:10.1076/13854046(200002)14:1;1-8;FT038

Horel, J. A. (1978). The neuroanatomy of amnesia. A critique of the hippocampal memory hypothesis. Brain 101, 403-445. doi:10.1093/brain/101.4.NP1

Horn, W. (1983). L-P-S Leistungsprüfsystem, 2nd Edn. Göttingen: Hogrefe.

Immordino-Yang, M. H., and Singh, V. (2013). Hippocampal contributions to the processing of social emotions. Hum. Brain Mapp. 34, 945-955. doi:10.1002/hbm.21485

Isaacs, E. B., Vargha-Khadem, F., Watkins, K. E., Lucas, A., Mishkin, M., and Gadian, D. G. (2003). Developmental amnesia and its relationship to degree of hippocampal atrophy. Proc. Natl. Acad. Sci. U.S.A. 100, 13060-13063. doi:10. $1073 /$ pnas. 1233825100

Jacob, H., and Pyrkosch, W. (1951). Frühe Hirnschäden bei Strang-tod und in der Agonie [Early brain damage after death by strangulation and during agony]. Arch. Psychiatr. Z. Neurol. 187, 177-186. doi:10.1007/ BF00343760

Jacobson, R. (1986). Disorder of facial recognition, social behaviour and affect after combined bilateral amyg-dalotomy and subcaudate tracto-tomy - a clinical and experimental study. Psychol. Med. 16, 439-450. doi:10.1017/S0033291700009272

Jänicke, C. (2001). Die Entwicklung des Bielefelder Famous Faces Test. Diploma thesis, University of Bielefeld. Available at: http://ebookbrowse.com/die-entwick lung-des-bielefelder-famous-facestest-pdf-d92434850

Janke, W., and Debus, D. (1978). Eigenschaftswörterliste (EWL-N). Göttingen: Hogrefe.

Kalbe, E., Brand, M., Hilker, R., and Kessler, J. (2001). "Theory of Mind"-Defizite bei Parkinson-Patienten: ein frühes Krankheitssymptom? Akt. Neurol. 28(Suppl.1), 49.

Kalbe, E., Brand, M., and Kessler, J. (2002). Zahlenverarbeitungs-und Rechentest (ZRT). Göttingen: Beltz.

Kalbe, E., Grabenhorst, F., Brand, M., Kessler, J., Hilker, R., and Markowitsch, H. J. (2007). Elevated emotional reactivity in affective but not cognitive components of theory of mind: a psychophysiological study. J. Neuropsychol. 1(Pt 1), 27-38. doi:10.1348/174866407X180792

Kaplan, E., Goodglass, H., and Weintraub, S. (1983). The Boston Naming Test. Philadelphia, PA: Lea and Febiger.

Keenan, J. P., Rubin, J., Racioppi, C., Johnson, A., and Barnacz, A. (2005). The right hemisphere and the dark side of consciousness. Cortex 41, 695-704. doi:10.1016/S00109452(08)70286-7

Kemp, J., Berthel, M. C., Dufour, A., Despres, O., Henry, A., Namer, I. J., et al. (2012). Caudate nucleus and social cognition: neuropsychological and SPECT evidence from a patient with focal caudate lesion. Cortex 49, 559-571. doi:10.1016/j.cortex.2012.01.004

Knight, J. B., Ethridge, L. E., Marsh, R. L., and Clementz, B. A. (2010). Neural correlates of attentional and mnemonic processing in event-based prospective memory. Front. Hum. Neurosci. 4:5. doi:10.3389/neuro.09.005.2010

Koenigs, M., and Tranel, D. (2007). Irrational economic decisionmakingafterventromedialprefrontal damage: evidence from the ultimatum game. J. Neurosci. 27, 951-956.
doi:10.1523/JNEUROSCI.4606-06. 2007

Kopelman, M. D., Wilson, B. A. and Baddeley, A. D. (1990). The Autobiographical Memory Interview. Bury St. Edmunds: Thames Valley Test Company.

Kritchevsky, M., Chang, J., and Squire, L. R. (2004). Functional amnesia: clinical description and neuropsychological profile of 10 cases. Learn Mem. 11, 213-226. doi: 10.1101/lm. 71404

Kuljis, R. O. (1994). Lesions in the pul-vinar in patients with Alzheimer's disease. J. Neuropathol. Exp. Neurol. 53, 202-211. doi:10.1097/00005072-19940300000012

Kupfer, J., Brosig, B., and Brähler, E. (2001). Toronto-Alexithymie-Skala26. Göttingen: Hogrefe.

Kwan, D., Carson, N., Addis, D. R., and Rosenbaum, R. S. (2010). Deficits in past remembering extend to future imagining in a case of developmental amnesia. Neuropsycholo-gia 48, 3179-3186. doi:10.1016/j.neuro psychologia.2010.06.011

Labudda, K., Mertens, M., Janszky, J., Bien, C. G., and Woermann, F. G. (2012). Atypical language lateralisation associated with right fronto-temporal grey matter increases - a combined fMRI and VBM study in left-sided mesial temporal lobe epilepsy patients. Neuroimage 59, 728-737. doi:10.1016/j.neuroimage.2011.07.05

Lanting, S., Crossley, M., Morgan, D., and Cammer, A. (2011). Aboriginal experiences of aging and dementia in a context of sociocultural change: qualitative analysis of key informant group interviews with Aboriginal seniors. J. Cross Cult. Gerontol. 26, 103-117. doi:10.1007/s10823010-9136-4

Lanting, S., O'Connell, M. E., and Cross-ley, M. (2010). Remembering to remember: performance on a newly developed measure of prospective memory measure in healthy adults and a clinical dementia sample. Paper Presented at the Rotman Conference on the Frontal Lobes, Toronto.

Laukka, P., Ahs, F., Furmark, T. and Fredrikson, M. (2011). Neurofunctional correlates of expressed vocal affect in social phobia. Cogn Affect. Behav. Neurosci. 11, 413-425. doi:10.3758/s13415-011-0032-3

Lebrun-Givois, C., Guillery-Girard, B., Thomas-Anterion, C., and Laurent, B. (2008). Knowing without remembering: the contribution of developmental amnesia. Rev. Neurol. (Paris) 164(Suppl. 3),
S114-S118. doi:10.1016/S0035 3787(08)73301-0

Lehrl, S. (2005). MehrfachwahlWortschatz-Intelligenztest (MWT-B). Balingen: Spitta Verlag.

Lemogne, C., Piolino, P., Friszer, S., Claret, A., Girault, N., Jouvent, R., et al. (2006). Episodic autobiographical memory in depression: specificity, autonoetic consciousness, and self perspective. Conscious. Cogn. 15, 258-268. doi:10.1016/j.concog.2005.07.005

Leplow, B., and Dierks, C. (1997). Diagnostik des Altgedáchtnisses mit der endgültigen Langund Kurz-form des "Kieler Altgedächtnistests." Diagnostica 43, 192-210.

Levine, B., Black, S. E., Cabeza, R., Sin-den, M., McIntosh,A R., Toth, J. P., et al. (1998). Episodic memory and the self in a case of isolated retrograde amnesia. Brain 121, 1951-1973. doi:10.1093/brain/121.10.1951

Levine, B., Svoboda, E., Turner, G. R., Mandic, M., and Mackey, A. (2009). Behavioral and functional neuroanatomical correlates of anterograde autobiographical memory in isolated retrograde amnesic patient M.L. Neuropsy-chologia 47, 2188-2196. doi:10.1016/j.neuropsychologia. 2008.12.026

Lezak, M. D. (1995). Neuropsychological Assessment. Oxford: Oxford University Press.

Lück, H. E. (2006). Die HeiderSimmel-Studie in neueren Rep-likationen. Gruppendynamik Organ. 37, 185-196. doi:10.1007/s11612-006-0021-0

Macey, P. M., Woo, M. A., Macey, K. E., Keens, T. G., Saeed, M. M., Alger, J. R., et al. (2005). Hypoxia reveals posterior thalamic, cerebellar, midbrain, and limbic deficits in congenital central hypoventilation syndrome. J. Appl. Physiol. 98, 958-969. doi:10.1152/japplphysiol.00969.2004

Maguire, E. A., Vargha-Khadem, F., and Hassabis, D. (2010). Imaging fictitious and future experiences: evidence from developmental amne-sia. Neuropsychologia 48, 3187-3192. doi:10.1016/j.neuro psychologia.2010.06.037

Maren, S., and Holt, W. G. (2004). Hippocampus and Pavlovian fear conditioning in rats: muscimol infusions into the ventral, but not dorsal, hippocampusimpair the acquisition of conditional freezing to an auditory conditional stimulus. Behav. Neurosci. 118, 97-110. doi:10.1037/0735-7044.118.1.97 
Markowitsch, H. J. (1985). Der Fall H.M. im Dienste der Hirnforschung [Case H.M. as serving brain research]. Naturwiss. Rundsch. 38, 410-416.

Markowitsch, H. J. (2003). "Memory: disturbances and therapy," in Neurological Disorders: Course and Treatment, 2nd Edn, eds T. Brandt, L. Caplan, J. Dichgans, H. C. Diener, and C. Kennard (San Diego: Academic Press), 287-302.

Markowitsch, H. J., and Staniloiu, A. (2011a). Memory, autonoetic consciousness, and the self. Consciousn. Cogn. 20, 16-39. doi:10.1016/j. concog.2010.09.005

Markowitsch, H. J., and Staniloiu, A. (2011b). Amygdala in action: relaying biological and social significance to autobiographic memory. Neuropsychologia 49, 718-733. doi:10.1016/j.neuro psychologia.2010.10.007

Markowitsch, H. J., and Staniloiu, A. (2013). The impairment of recollection in functional amnesic states. Cortex (in press). doi:10.1016/j.cortex.2012.05.020

Markowitsch, H. J., and Staniloiu, S. (2012). Amnesic disorders. Lancet 380, 1429-1440. doi:10.1016/S01406736(11)61304-4

Markowitsch, H. J., Thiel, A., Reinkemeier, M., Kessler, J., Koyuncu, A., and Heiss, W. D. (2000). Right amygdalar and temporofrontal activation during autobiographic, but not during fictitious memory retrieval. Behav. Neurol. 12, 181-190.

Markowitsch, H. J., von Cramon, D. Y., Hofmann, E., Sick, C.-D., and Kinzler, P. (1990). Verbal memory deterioration after unilateral infarct of the internal capsule in an adolescent. Cortex 26, 597-609.

Markowitsch, H. J., von Cramon, D. Y., and Schuri, U. (1993). Mnes-tic performance profile of a bilateral diencephalic infarct patient with preserved intelligence and severe amnesic disturbances. J. Clin. Exp. Neuropsychol. 15, 627-652. doi:10.1080/01688639308402586

Markowitsch, H. J., WeberLuxenburger, G., Ewald, K., Kessler, J., and Heiss, W.-D. (1997). Patients with heart attacks are not valid models for medial temporal lobe amnesia. A neuropsychological and FDG-PET study with consequences for memory research. Eur. J. Neurol. 4, 178-184. doi:10.1111/j.14681331.1997.tb00324.x

Martens, M. A., Wilson, S. J., Dudgeon, P., and Reutens, D. C. (2009). Approachability and the amygdala: insights from Williams syndrome.
Neuropsychologia 47, 2446-2453. doi:10.1016/j.neuropsychologia. 2009.04.017

Martins, S., Guillery-Girard, B., Jambaque, I., Dulac, O., and Eustache, F. (2006). How children suffering severe amnesic syndrome acquire new concepts? Neuropsychologia 44, 2792-2805. doi:10.1016/j.neuropsychologia. 2006.05.022

McKinlay, A., McVittie, C., and Della Sala, S. (2009). Imaging the future: does a qualitative analysis add to the picture? J. Neuropsychol. 4(Pt 1), 1-13. doi:10.1348/174866409X468395

Milner, B., Corkin, S., and Teuber, H. L. (1968). Further analysis of the hippocampal amnesic syndrome: fourteen year follow-up study of H.M. Neuropsychologia 6, 215-234. doi:10.1016/0028-3932(68)90021-3

Mitrushina, M., Boone, K. B., Razani, J., and D'Elia, L. F. (2005). Handbook of Normative Data for Neu-ropsychological Assessment, 2nd Edn. Oxford: Oxford University Press.

Mori, E., Ikeda, M., Hirono, N., Kita-gaki, H., Imanura, T., and Shimo-mura, T. (1999). Amygdalar volume and emotional memory in Alzheimer's disease. Am. J. Psychiatry 156, 216-222.

Nelson, H. E. (1976). A modified card sorting test sensitive to frontal lobe defects. Cortex12, 313-324.

Nelson, H. E. (1982). National Adult Reading Test (NART). Windsor: NFER-Nelson.

Nelson, K. (2003). "Narrative and self, myth and memory: emergence of the cultural self," in The Development of Autobiographical Memory and Self-Understanding, eds R. Fivush and C. Haden (Hillsdale, NJ: Lawrence Erlbaum Associates), 3-28.

Nelson, K. (2005). "Evolution and development of human memory systems," in Origins of the Social Mind, eds B. J. Ellis and D. F. Björklund (New York: Guilford Press), 319-345.

Nelson, K., and Fivush, R. (2004). The emergence of autobiographical memory: a social cultural developmental theory. Psychol. Rev. 111, 486-511. doi:10.1037/0033-295X.111.2.486

Newen, A., and Schlicht, T. (2009). Understanding other minds: a criticism of Goldman's simulation theory and an outline of the person model theory. Grazer Philos. Stud. 79, 209-242.

Nguyen, M. N., Hori, E., Matsumoto, J., Tran, A. H., Ono, T., and Nishijo,
H. (2013). Neuronal responses to face-like stimuli in the monkey pulvinar. Eur. J. Neurosci. 37, 35-51. doi:10.1111/ejn.12020

Nyberg, L., Kim, A. S., Habib, R. Levine, B., and Tulving, E. (2010). Consciousness of subjective time in the brain. Proc. Natl. Acad. Sci. U.S.A. 107, 22356-22359. doi:10.1073/pnas.1016823108

Olsen, R. K., Moses, S. N., Riggs, L., and Ryan, J. D. (2012). The hippocampus supports multiple cognitive processes through relational binding and comparison. Front. Hum. Neurosci. 6:146. doi:10.3389/fnhum.2012.00146

Oosterbeek, H., Sloof, R., and van de Kuilen, G. (2004). Cultural differences in ultimatum game experiments: evidence from a meta-analysis. Exp. Econ. 7, 171-188. doi:10.1023/B:EXEC. 0000026978.14316.74

Osterrieth, P. A. (1944). Le test de copie d'une figure complex: contribution à létude de la perception et de la mémoire. Arch. Psychol. (Geneve) 30, 286-356.

Paulmann, S., Pell, M. D., and Kotz, S. A. (2008). Functional contributions of the basal ganglia to emotional prosody: evidence from ERPs. Brain Res. 1217, 171-178. doi:10.1016/j.brainres.2008.04.032

Paulus, C. (2012). Saarbrücker Persönlichkeits-Fragebogen $z u$ Empathie (SPF). Saarbrücken: Universität des Saarlands. Available at: http://bildungswissenschaften. uni-saarland.de/personal/paulus/ empathy/SPF.html

Paus, T. (2010). Growth of white matter in the adolescent brain: myelin or axon? Brain Cogn. 72, 26-35. doi:10.1016/j.bandc.2009.06.002

Perner, J. (2000). "Memory and theory ofmind,"inTheOxfordHandbookof Memory, eds E. Tulving and F. I. M. Craik (New York: Oxford University Press), 297-314.

Perry, D., Hendler, T., and Shamay-Tsoory, S. G. (2011). Projecting memories: the role of hippocampus in emotional mentalizing. Neuroimage 54, 1669-1676. doi:10.1016/j.neuro image.2010.08.057

Pessoa, L. (2008). On the relationship between emotion and cognition. Nat. Rev. Neurosci. 9, 148-158. doi:10.1038/nrn2317

Pessoa, L. (2011). Reprint of: emotion and cognition and the amygdala: from "what is it?" to "what's to be done?" Neuropsycholo-gia 49, 681-694. doi:10.1016/j.neuro psychologia.2011.02.030
Pessoa, L., and Adolphs, R. (2010). Emotion processing and the amygdala: from a "low road" to "many roads" of evaluating biological significance. Nat. Rev. Neurosci. 11, 773-783. doi:10.1038/nrn2920

Picard, L., Mayor-Dubois, C., Maeder, P., Kalenzaga, S., Abram, M., Duval, C., et al. (2012). Functional indepen-dence within the self-memory system: new insights from two cases of developmental amnesia. Cortex. doi:10.1016/j.cortex.2012.10.003

Quian Quiroga, R. (2012). Concept cells: the building blocks of declarative memory functions. Nat. Rev. Neurosci. 13, 587-597. doi:10.1038/nrn3251

Rabin, J. S., Braverman, A., Gilboa, A., Stuss, D. T., and Rosenbaum, R. S. (2012). Theory of mind development can withstand compromised episodic memory development. Neuropsychologia 50, 3781-3785. doi:10.1016/j.neuro psychologia.2012.10.016

Rabin, J. S., Gilboa, A., Stuss, D., Mar, R. A., and Rosenbaum, R. S. (2010). Common and unique neural correlates of autobiographical memory and theory of mind. J. Cogn. Neurosci. 22, 1095-1111. doi:10.1162/jocn.2009. 21344

Rabin, J. S., and Rosenbaum, R. S. (2012). Familiarity modulates the functional relationship between theory of mind and autobiographical memory. Neuroimage 62, 520-529. doi:10.1016/j.neuroimage. 2012.05. 002

Reinhold, N., and Markowitsch, H. J. (2007). Emotion and consciousness in adolescent psychogenic amnesia. J. Neuropsychol. 1, 53-64. doi:10. 1348/174866407X180819

Reinhold, N., and Markowitsch, H. J. (2008). Theory of mind and the sense of self [Letter to the Editor]. Science. [Online].

Reinhold, N., and Markowitsch, H. J. (2009). Retrograde episodic memory and emotion: a perspective from patients with dissociative amnesia. Neuropsychologia 47, 2197-2206. doi:10.1016/j.neuro psychologia.2009.01.037

Reiss, M., and Reiss, G. (2000). Zur Untersuchung der motorischen Asymmetrien. Fortschr. Neurol. Psy-chiatr. 68, 70-79. doi:10.1055/s2000-11648

Reitan, R. (1958). Validity of the trail making test as an indication of organic brain damage. Percept. Mot. Skills 8, 271-276. doi:10.2466/PMS.8.7. 271-276 
Rosenbaum, R. S., Carson, N., Abraham, N., Bowles, B., Kwan, D., Kohler, S., et al. (2011). Impaired event memory and recollection in a case of developmental amnesia. Neurocase 17, 394-409. doi:10.1080/13554794.2010.532138

Rosenbaum, R. S., Gilboa, A., Levine, B., Winocur, G., and Moscovitch, M. (2009). Amnesia as an impairment of detail generation and binding: Evidence from personal, fictional, and semantic narratives in K.C. Neuropsychologia 47, 2181-2187. doi: 10.1016/j. neuropsychologia.2008.11.028

Rosenbaum, R. S., Köhler, S., Schacter, D. L., Moscovitch, M., Westmacott, R., Black, S. E., et al. (2005). The case of K.C.: contributions of a memory-impaired person to memory theory. Neuropsychologia 43, 989-1021. doi:10.1016/j.neuro psychologia.2004.10.007

Rosenbaum, R. S., Stuss, D. T., Levine, B., and Tulving, E. (2007). Theory of mind is independent of episodic memory. Science 318, 1257. doi:10.1126/science.1148763

Ross, E. D., and Monnot, M. (2011). Affective prosody: what do comprehension errors tell us about hemispheric lateralization of emotions, sex and aging effects, and the role of cognitive appraisal. Neuropsychologia 49, 866-877. doi:10.1016/j.neuro psychologia.2010.12.024

Ross, L. A., and Olson, I. R. (2010). Social cognition and the anterior temporal lobes. Neuroimage 49, 3452-3462. doi:10.1016/ j.neuroimage.2009.11.012

Roth-Hanania, R., Davidov, M., and Zahn-Waxler, C. (2011). Empathy development from 8 to 16 months: early signs of concern for others. Infant Behav. Dev. 34, 447-458. doi:10.1016/j.infbeh.2011.04.007

Saalmann, Y. B., and Kastner, S. (2013). A role for the pulvinar in social cognition (commentary on Nguyen et al.). Eur. J. Neurosci. 37, 33-34. doi:10.1111/ejn.12072

Sadowska, L. (2001). Vaclav Vojta's neurokinesiological concept for the diagnosis and therapy of children with disturbances of motor development. Ortop. Traumatol. Rehabil. $3,519-526$.

Sarter, M., and Markowitsch, H. J. (1985a). The amygdala's role in human mnemonic processing. Cortex 21, 7-24.

Sarter, M., and Markowitsch, H. J. (1985b). The involvement of the amygdala in learning and memory: a critical review with emphasis on anatomical relations.
Behav. Neurosci. 99, 342-380. doi:10.1037/0735-7044.99.2.342

Saxe, R., Moran, J. M., Scholz, J., and Gabrieli, J. (2006). Overlapping and non-overlapping brain regions for theory of mind and self reflection in individual subjects. Soc. Cogn. Affect. Neurosci. 1, 229-234. doi:10.1093/scan/nsl034

Scheele, D., Mihov, Y., Kendrick, K. M., Feinstein, J. S., Reich, H., Maier, W., et al. (2012). Amygdala lesion profoundly alters altruistic punishment. Biol. Psychiatry 72, e5-e7. doi:10.1016/j.biopsych.2012.01.028

Schmidtke, K., and Vollmer-Schmolck, H. (1999). Autobiographisches Altgedáchtnisinterview und semantisches Altgedáchtnisinventar [Autobiographic old memory interview and semantic old memory inventory]. Z. Neuropsychol. 10, 13-23. doi:10.1024//1016-264X.10.1.13

Schore, A. N. (2002). Dysregulation of the right brain: a fundamental mechanism of traumatic attachment and the psychopathogene-sis of posttraumatic stress disorder. Aust. N. Z. J. Psychiatry 36, 9-30. doi:10.1046/j.14401614.2002.00996.x

Schulte-Rüther, M., Markowitsch, H. J., Shah, N. J., Fink, G. R., and Piefke, M. (2008). Gender differences in the functional neuroanatomy of emotional perspective taking. Neuroimage 14, 393-403.

Schuster, P. (1936). Beiträge zur Pathologie des Thalamus opticus II [Contributions to the pathology of the optic thalamus II]. Arch. Psychiatr. Nervenkr. 105, 550-622. doi:10.1007/BF01814378

Scoville, W. B., and Milner, B. (1957). Loss of recent memory after bilateral hippocampal lesions. J. Neurol. Neurosurg. Psychiatr. 20, 11-21. doi:10.1136/jnnp.20.1.11

Shallice, T., and Evans, M. E. (1978). The involvement of the frontal lobes in cognitive estimation. Cortex 14, 294-303.

Shamay-Tsoory, S. G., and AharonPeretz, J. (2007). Dissociable prefrontal networks for cognitive and affective theory of mind: a lesion study. Neuropsycholo-gia 45, 3054-3067. doi:10.1016/j.neuro psychologia.2007.05.021

Shamay-Tsoory, S. G., Aharon-Peretz, J., and Perry, D. (2009). Two systems for empathy: a double dissociation between emotional and cognitive empathy in inferior frontal gyrus versus ventromedial prefrontal lesions. Brain 132, 617-627. doi:10.1093/brain/ awn279
Shammi, P., and Stuss, D. T. (1999). Humour appreciation: a role of the right frontal lobe. Brain 122(Pt. 4), 657-666. doi:10.1093/brain/122.4.657

Sharot, T., Riccardi, A. M., Raio C. M., and Phelps, E. A. (2007) Neural mechanisms mediating optimism bias. Nature 450, 102-105 doi:10.1038/nature06280

Shaw, P., Lawrence, E. J., Radbourne, C., Bramham, J., Polkey, C. E., and David, A. S. (2004). The impact of early and late damage to the human amygdala on "theory of mind" reasoning. Brain 127, 1535-1548. doi:10.1093/brain/awh168

Siebert, M., Markowitsch, H. J., and Bartel, P. (2003). Amygdala, affect, and cognition: evidence from ten patients with Urbach-Wiethe disease. Brain 126, 2627-2637. doi:10.1093/brain/awg271

Smyth, G. E., and Stern, K. (1938). Tumours of the thalamus - a clinico-pathological study. Brain 61, 339-374. doi:10.1093/brain/61.4.339

Snitz, B. E., Hellinger, A., and Daum, I. (2002). Impaired processing of affective prosody in Korsakoff's syndrome. Cortex 38, 797-803. doi:10. 1016/S0010-9452(08)70046-7

Sollman, M. J., and Berry, D. T. R. (2011). Detection of inadequate effort on neuropsychological testing: a meta-analytic update and extension. Arch. Clin. Neuropsychol. 26, 774-789. doi:10.1093/arclin/acr066

Spitz, H. H., Webster, N. A., and Borys, S. V. (1982). Further studies of the Tower of Hanoi problemsolving performance of retarded young adults and nonretarded children. Dev. Psychol. 18, 922-930 doi:10.1037/0012-1649.18.6.922

Spreen, O., and Strauss, E. (1998). A Compendium of Neuropsychological Tests, 2nd Edn. New York: Oxford University Press.

Spreng, R. N., and Grady, C. L. (2010). Patterns of brain activity supporting autobiographical memory, prospection, and theory of mind, and their relationship to the default mode network. J. Cogn. Neurosci. 22, 1112-1123. doi:10.1162/jocn.2009.21282

Spreng, R. N., Mar, R. A., and Kim, A. S. N. (2008). The common neural basis of autobiographical memory, prospection, navigation, theory of mind and the default mode: a quantitative meta-analysis. J. Cogn. Neurosci. 21, 489-510. doi:10.1162/jocn.2008.21029

Squire, L. R., van der Horst, A. S., McDuff, S. G. R., Frascino, J. C.,
Hopkins, R. O., and Mauldin, K. N. (2010). Role of the hippocampus in remembering the past and imagining the future. Proc. Natl. Acad. Sci. U.S.A. 107, 19044-19048. doi:10.1073/pnas.1014391107

Staniloiu, A., Borsutzky, S., and Markowitsch, H. J. (2010a). "Dissociative memory disorders and immigration," in ASCSO9: Proceedings of the 9th Conference of the Australasian Society for Cognitive Science, eds W. Christiansen, E. Schier, and J. Sutton (Sydney: Centre for Cognitive Sciences), 316-324.

Staniloiu, A., Markowitsch, H. J., and Brand, M. (2010b). Psy-chogenic amnesia - a malady of the constricted self. Conscious. Cogn. 19, 778-801. doi:10.1016/j.concog.2010.06.024

Staniloiu, A., and Markowitsch, H. J. (2012). Towards solving the riddle of forgetting in functional amnesia: recent advances and current opinions. Front. Psychol. 3:403. doi:10.3389/fpsyg.2012.00403

Stern, K. (1939). Severe dementia associated with bilateral symmetrical degeneration of the thalamus. Brain 62, 157-171. doi:10.1093/brain/62.2.157

Stone, V. E., Baron-Cohen, S., and Knight, R. T. (1998). Frontal lobe contributions to theory of mind. J. Cogn. Neurosci. 10, 640-656. doi:10.1162/089892998562942

Stroop, J. R. (1935). Studies of interference in serial verbal reaction. J. Exp. Psychol. 18, 643-662. doi:10.1037/h0054651

Stuss, D. T., Gallup, G. G. Jr., and Alexander, M. P. (2001). The frontal lobes are necessary for "theory of mind." Brain 124(Pt 2), 279-286.

124.2.279

Stuss, D. T., and Levine, B. (2002). Adult clinical neuropsychology: lessons from studies of the frontal lobes. Аnnu. Rev. Psychol. 53, 401-433. doi:10.1146/annurev. psych.53.100901.135220

Suddendorf, T., Addis, D. R., and Corballis, M. C. (2009). Mental time travel and the shaping of the human mind. Philos. Trans. R. Soc. Lond. B Biol. Sci. 364, 1317-1324. doi:10.1098/rstb.2008. 0301

Temizyürek, K. (2003). Neutral and Emotional Picture Story Recall. Unpublished thesis, University of Bielefeld.

Temple, C. M., and Richardson, P. (2006). Developmental amnesia: Fractionation of developing memory systems. $\operatorname{Cog} n$. 
Neuropsychol. $\quad 23, \quad 762-788$. doi:10.1080/02643290500538315

Tewes, U. (1991). Hamburg-WechslerIntelligenztest für Erwachsene Revision (HAWIE-R). Göttingen: Hogrefe.

Tsukiura, T., Shigemune, Y., Nouchi, R., Kambara, T., and Kawashima, R. (2012). Insular and hippocampal contributions to remembering people with an impression of bad personality. Soc. Cogn. Affect. Neurosci. doi:10.1093/scan/nss025

Tulving, E. (2005). "Episodic memory and autonoesis: uniquely human?" in The Missing Link in Cognition: Evolution of Self-Knowing Consciousness, eds H. Terrace and J. Met-calfe (New York: Oxford University Press), 3-56.

Uekermann, J., Channon, S., and Daum, I. (2006). Humor processing, mentalizing, and executive function in normal aging. J. Int. Neuropsychol. Soc. 12, 184-191. doi:10.1017/S1355617706060280

van Buren, J. M., and Borke, R. C. (1972). Variations and Connections of the Human Thalamus, Vol. 1: The Nuclei and Cerebral Connections of the Human Thalamus. Berlin: Springer.

Vargha-Khadem, F., Gadian, D. G., Watkins, K. E., Connelly, A., van Paesschen, W., and Mishkin, M. (1997). Differential effects of early hippocampal pathology on episodic and semantic memory. Science 277, 376-380. doi:10.1126/science.277.5324.376

Vargha-Khadem, F., Salmond, C. H., Watkins, K. E., Friston, K. J., Gadian, D. G., and Mishkin, M. (2003). Developmental amnesia: effect of age at injury. Proc. Natl. Acad. Sci. U.S.A. 100, 10055-10060. doi:10.1073/pnas. 1233756100

Viard, A., Desgranges, B., Eustache, F., and Piolino, P. (2012). Factors affecting medial temporal lobe engagement for past and future episodic events: an ALE meta-analysis of neuroimaging studies. Brain Cogn. 80, 111-125. doi:10.1016/j.bandc.2012. 05.004

Vieth, M. (2003). Die Evolution von Fairnessnormen im Ultimatum-spiel. Z. Soziol. 32, 346-367.

Voit, T., Lemburg, P., Neuen, E., Lumenta, C., and Stork, W. (1987). Damage of thalamus and basal ganglia in asphyxiated full-term neonates. Neuropediatrics 18, 176-181. doi:10.1055/s-2008-1052475

von Cramon, D. Y., Markowitsch, H. J., and Schuri, U. (1993). The possible contribution of the septal region to memory. Neuropsychologia 31, 1159-1180. doi:10.1016/00283932(93) $90065-8$ von Cramon, D. Y., and Zihl, J. (1989). Neuropsychologische Rehabilitation. Berlin: Springer.

Ward, P., Seri And S., and Cavanna, A. E. (2012). Functional neuroanatomy and behavioural correlates of the basal ganglia: evidence from lesion studies. Behav. Neurol. 26, 219-223. doi:10.3233/ BEN-2012-12026

Wechsler, D. (1981). Wechsler adult intelligence scale-revised. New York, NY: Psychological Corporation.

Wheeler, M. A., Stuss, D. T., and Tulving, E. (1997). Toward a theory of episodic memory: the frontal lobes and autonoetic consciousness. Psychol. Bull. 121, 331-354. doi:10.1037/0033-2909.121.3.331

Willoughby, K. A., Desrocher, M., Levine, B., and Rovet, J. F. (2012). Episodic and semantic autobiographical memory and everyday memory during late childhood and early adolescence. Front. Psychol 3:53. doi:10.3389/fpsyg.2012.00053

Wilson, B. A., Cockburn, J., and Baddeley, A. D. (1985). The Rivermead Behavioural Memory Test. Reading: Thames Valley Test Company.

Zingerle, H. (1912). Über einseitigen Schläfenlappendefekt beim Menschen [On a unilateral defect of the temporal lobe in man]. J. Psychol. Neurol. 18, 205-235.
Zola-Morgan, S., Squire, L. R., and Mishkin, M. (1982). The neuroanatomy of amnesia: the amygdala-hippocampus vs. temporal stem. Science 218, 1337-1339. doi:10.1126/science.6890713

Conflict of Interest Statement: The authors declare that the research was conducted in the absence of any commercial or financial relationships that could be construed as a potential conflict of interest.

Received: 13 November 2012; accepted: 24 May 2013; published online: 24 June 2013.

Citation: Staniloiu A, Borsutzky S, Woermann FG and Markowitsch HJ (2013) Social cognition in a case of amnesia with neurodevelopmental mechanisms. Front. Psychol. 4:342. doi: 10.3389/fpsyg.2013.00342

This article was submitted to Frontiers in Cognition, a specialty of Frontiers in Psychology.

Copyright (C) 2013 Staniloiu, Borsutzky, Woermann and Markowitsch. This is an open-access article distributed under the terms of the Creative Commons Attribution License, which permits use, distribution and reproduction in other forums, provided the original authors and source are credited and subject to any copyright notices concerning any thirdparty graphics etc. 